San Jose State University

SJSU ScholarWorks

\title{
Pilot Study of a Breastfeeding Support Training Program Designed Particularly for Infants with Common Congenital Anomalies and Defects
}

\author{
Gretchen Nelson Ezaki \\ California State University, Northern California Consortium Doctor of Nursing Practice
}

Follow this and additional works at: https://scholarworks.sjsu.edu/etd_doctoral

Part of the Maternal, Child Health and Neonatal Nursing Commons

\section{Recommended Citation}

Ezaki, Gretchen Nelson, "Pilot Study of a Breastfeeding Support Training Program Designed Particularly for Infants with Common Congenital Anomalies and Defects" (2019). Doctoral Projects. 120.

DOI: https://doi.org/10.31979/etd.gu4j-h948

https://scholarworks.sjsu.edu/etd_doctoral/120

This Doctoral Project is brought to you for free and open access by the Master's Theses and Graduate Research at SJSU ScholarWorks. It has been accepted for inclusion in Doctoral Projects by an authorized administrator of SJSU ScholarWorks. For more information, please contact scholarworks@sjsu.edu. 


\begin{abstract}
STUDY OF A BREASTFEEDING SUPPORT TRAINING PROGRAM DESIGNED PARTICULARLY FOR INFANTS WITH COMMON CONGENITAL ANOMOLIES AND DEFECTS
\end{abstract}

The American Academy of Pediatrics (American Academy of Pediatrics [AAP], 2018), the World Health Organization (World Health Organization [WHO)], 2018), and The March of Dimes (March of Dimes, 2016) recommend exclusive breastfeeding for the first six months of life. In 2014, $79 \%$ of women in the United States began breastfeeding their infants, but only $40.7 \%$ and $18.8 \%$ continued breastfeeding exclusively at three and six months respectively (Centers for Disease Control and Prevention, 2017). This doctoral project promotes breastfeeding by creating and testing simple teaching algorithms for training registered nurses to support breastfeeding, including for infants with trisomy 21 , congenital heart defects, and oral cleft defects. To validate the new algorithms, two focus groups were held with a total of nineteen registered nurses in Central California (four registered nurses in one focus group and fifteen in the other). Participants tended to be older with an average of 29.6 years of experience primarily in obstetrical nursing. A qualitative study showed the nurses enjoyed learning through role play and felt they learned valuable information. The biggest barrier to learning identified was feeling overwhelmed by the amount of information presented in the algorithm for infants with common congenital anomalies and defects.

Gretchen Ezaki

May 2019 



\title{
PILOT STUDY OF A BREASTFEEDING SUPPORT TRAINING PROGRAM DESIGNED PARTICULARLY FOR INFANTS WITH COMMON CONGENITAL ANOMALIES AND DEFECTS
}

\author{
by \\ Gretchen Nelson Ezaki
}

\begin{abstract}
A project
submitted in partial

fulfillment of the requirements for the degree of

Doctor of Nursing Practice

California State University, Northern Consortium

Doctor of Nursing Practice
\end{abstract}

May 2019 


\section{APPROVED \\ For the California State University, Northern Consortium Doctor of Nursing Practice:}

We, the undersigned, certify that the project of the following student meets the required standards of scholarship, format, and style of the university and the student's graduate degree program for the awarding of the Doctor of Nursing Practice degree.

$\frac{\text { Gretchen Nelson Ezaki }}{\text { Project Author }}$
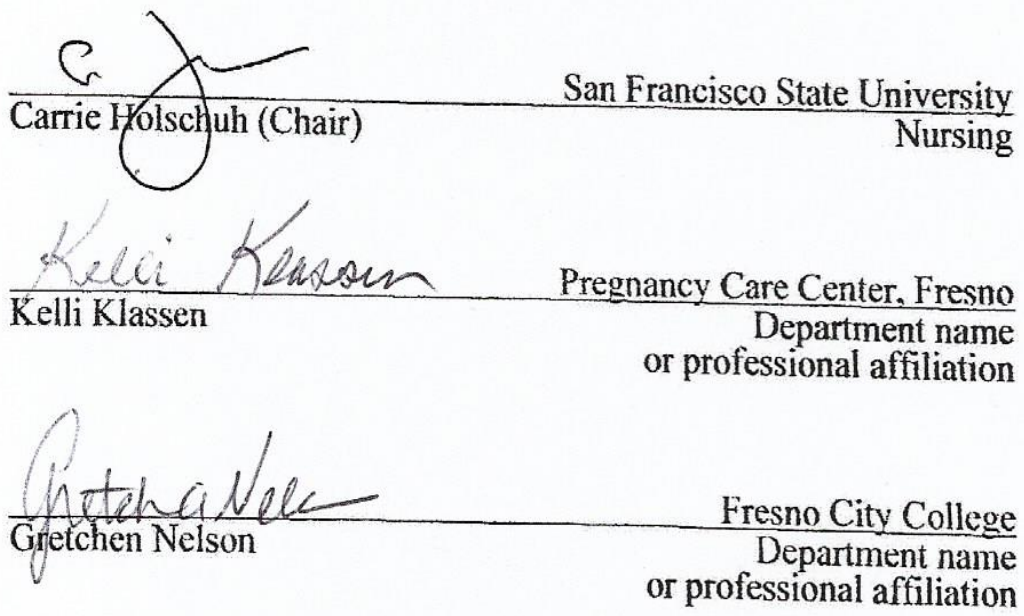


\section{AUTHORIZATION FOR REPRODUCTION}

\section{OF DOCTORAL PROJECT}

$\underline{\mathrm{X}} \quad$ I grant permission for the reproduction of this project in part or in its entirety without further authorization from me, on the condition that the person or agency requesting reproduction absorbs the cost and provides proper acknowledgment of authorship.

Permission to reproduce this project in part or in its entirety must be obtained from me.

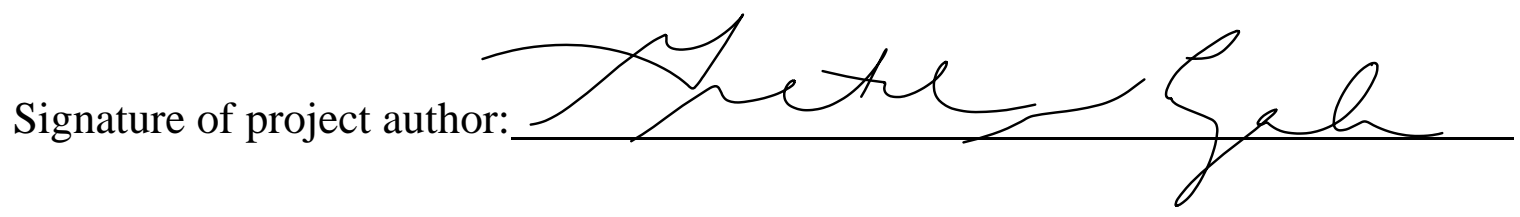




\section{ACKNOWLEDGMENTS}

The drawings used in the algorithms (except the trisomy 21 and oral cleft defects images) were created for this project by Anastasia Dobrencu and used with permission. 


\section{TABLE OF CONTENTS}

Page

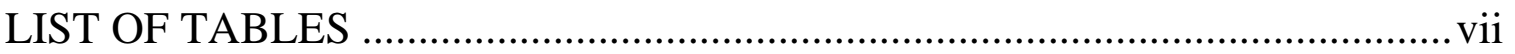

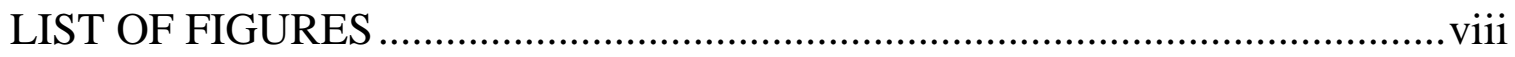

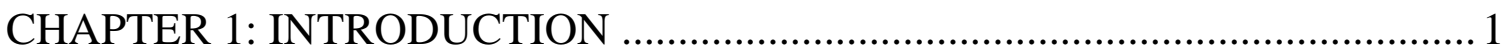

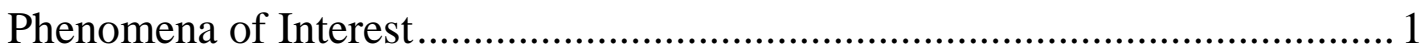

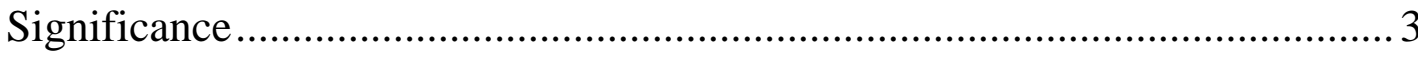

Research Question....................................................................................... 4

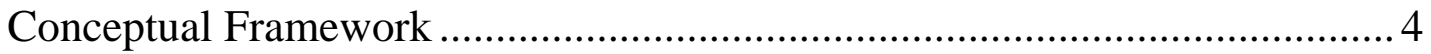

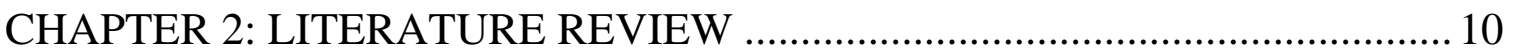

Reasons for Cessation of Breastfeeding......................................................... 10

Breastfeeding Infants with Congenital Defects and Anomalies ..................... 15

Teaching Through Simulation/Role Play .......................................................2 20

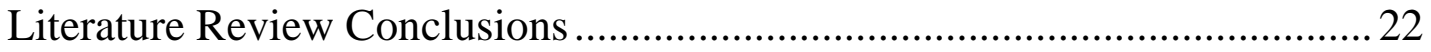

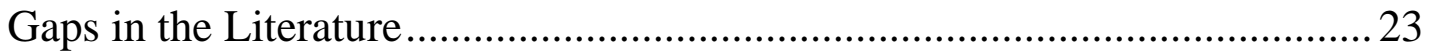

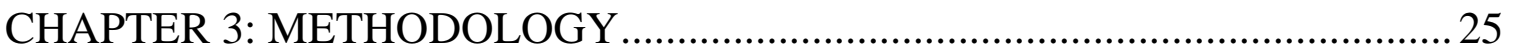

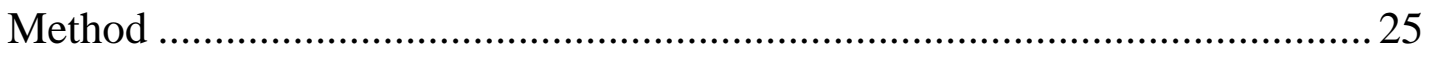

Sample and Subject Confidentiality ...........................................................25

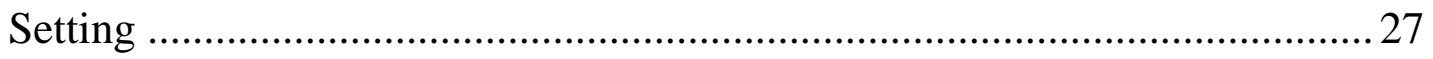

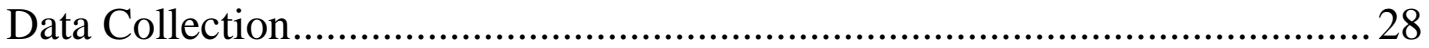

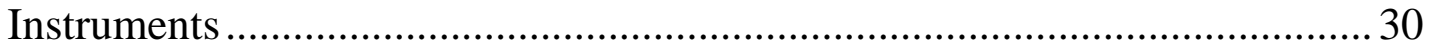

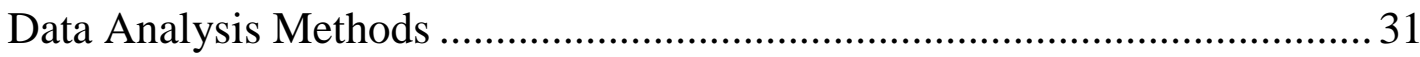

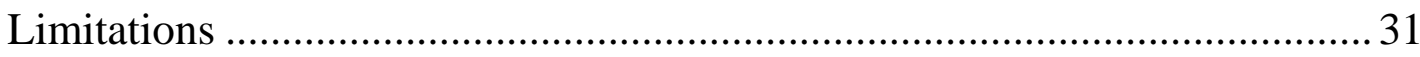

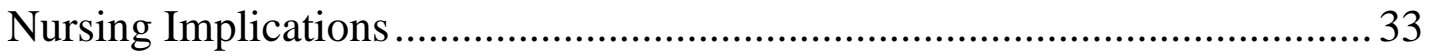

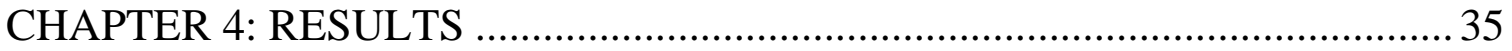




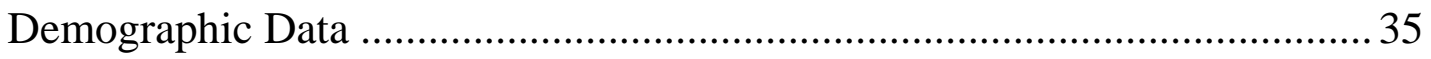

Breastfeeding Knowledge pre- and posttests ................................................... 38

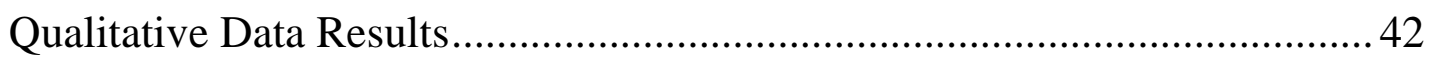

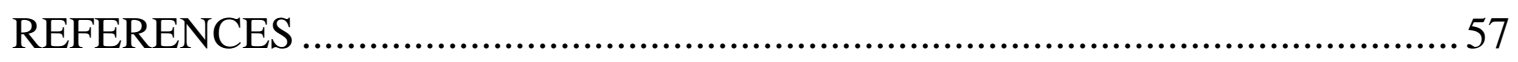

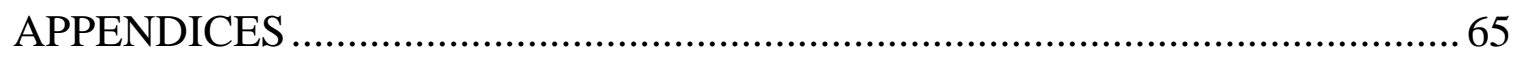

APPENDIX A: BREASTFEEDING TEACHING ALGORITHMS .....................66

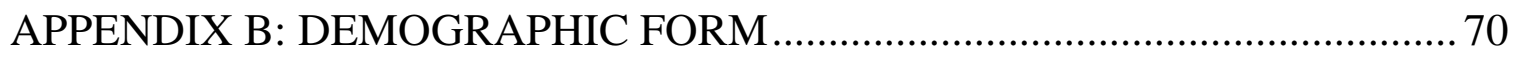

APPENDIX C: BREASTFEEDING KNOWLEDGE TEST ................................ 72

APPENDIX D: OBJECTIVE STRUCTURED CLINICAL SKILLS EXAM

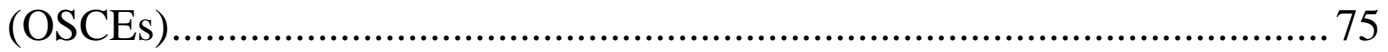

APPENDIX E: GUIDED DISCUSSION QUESTIONS .................................... 78

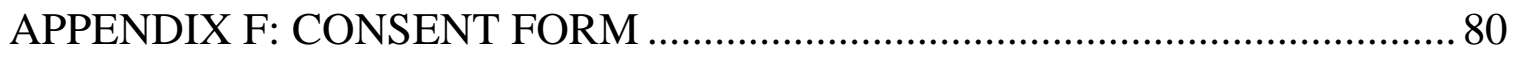

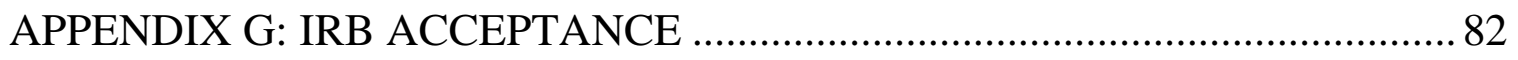

APPENDIX H: PREGNANCY CARE CENTER APPROVAL ........................... 84

APPENDIX I: FACILITATORS AND BARRIERS ………................................. 86

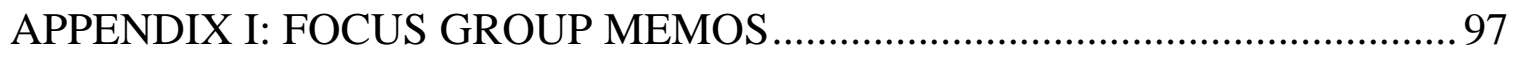

APPENDIX J: PERMISSISON TO USE IMAGE................................................. 101 


\section{LIST OF TABLES}

Table 1 Demographic Breakdown of Participating Registered Nurses................ 35

Table 2 Breastfeeding Knowledge Paired Samples Combined Focus Groups ..... 39

Table 3 Breastfeeding Knowledge Paired Samples t-test Combined Focused

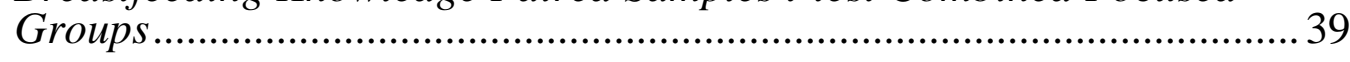

Table 4 Pre- and Posttest Correlations Combinded Focus Groups .................... 400

Table 5 Paired Sample Using All Questions for Focus Group 1 ...........................41

Table 6 Paired Samples Using All Questions for Focus Group 2 ........................ 41

Table 7 Pre-and Posttest Correlations Focus Group 1 Without Questions 7 and 9 ......

Table 8 Pre-and Posttest Correlations Focus Group 2 Without Questions 7

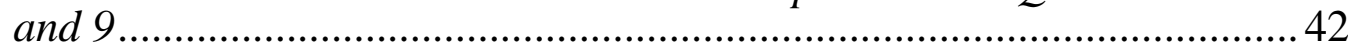

Table 9 Focus Group Data Analysis_Identified Themes .................................... 44 


\section{LIST OF FIGURES}

Page

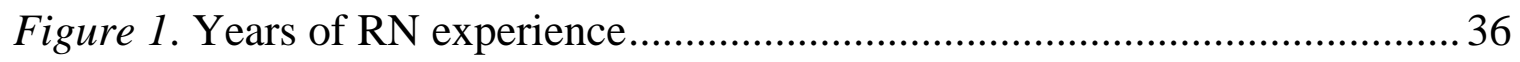

Figure 2. Highest degree in nursing .................................................................. 37

Figure 3. Word cloud of focus group discussion word frequency ......................... 43 


\section{CHAPTER 1: INTRODUCTION}

\section{Phenomena of Interest}

The beneficial effects of breastfeeding for infant and mother have been extensively studied and are widely accepted. The American Academy of Pediatrics (AAP) (2018a), the March of Dimes (2016), and the World Health Organization (WHO) (2018) recommend exclusive breastfeeding for the first six months of an infant's life. In 2014, 79\% of women in the United States began breastfeeding their infants, but only $40.7 \%$ and $18.8 \%$ continued breastfeeding exclusively at three and six months, respectively (Centers for Disease Control and Prevention, 2017). Along with the general percentages, Odom, Scanlon, Perrine, and Grummer-Strawn (2013) found women who plan to breastfeed do not meet their own breastfeeding goals. A meta-analysis by Brockway, Benzies, and Hayden (2017) confirms that women are not breastfeeding as long as recommended nor as long as they wanted and intended.

The AAP, based on WHO data and the United Nation's Millennium Development Goal to decrease infant mortality, developed Helping Babies Survive (AAP, 2018b). Helping Babies Survive is comprised of three courses taught to nurses, midwives, and birth attendants using simple pictorial algorithms and role playing. Helping Babies Survive is designed to decrease infant mortality during the first twenty-four hours of life in undeveloped and developing countries with the highest stillbirth and neonatal mortality rates. Helping Babies Survive has demonstrated phenomenal results with a decline of neonatal mortality of $47 \%$ and $46 \%$ respectively in parts of Ethiopia and India where it has been implemented (AAP, 2018b). 
Breastfeeding is a component of Helping Babies Survive; however, it is only one small piece in the algorithm for providing newborn care during the first twenty-four hours of life. This doctoral project has created breastfeeding algorithms patterned after Helping Babies Survive to train registered nurses in teaching, assessing, and supporting breastfeeding, particularly among infants with common congenital anomalies and defects. Even though Helping Babies Survive is designed for use in developing and undeveloped countries, simple algorithms to teach breastfeeding are applicable to all communities because breastfeeding is recommended for all babies. Mothers of infants with defects that increase the difficulty of breastfeeding will benefit from these algorithms regardless of their nation of origin. The new breastfeeding algorithms can be used to augment Helping Babies Survive or independently of Helping Babies Survive, especially for infants with feeding dysfunction related to a common congenital anomaly or defect.

Young mothers with limited education living in low-income communities are a population at high risk for not breastfeeding their infants (Centers for Disease Control and Prevention, 2014). These women likely will not and potentially cannot read a pamphlet on breastfeeding written at a high reading level with a lot of text. The algorithms for this project are designed with simple drawings and few words. This project, while not specifically designed for lowincome young mothers, might be beneficial in improving breastfeeding rates among this at-risk population.

This project promotes the health of women and infants through supporting breastfeeding. It is a pilot study to improve a program to train nurses to support breastfeeding, including for infants with common congenital anomalies and 
defects. The program utilizes simple, pictorial breastfeeding teaching algorithms (see Appendix A) and is taught and assessed through role play. Three algorithms were developed to train registered nurses in teaching breastfeeding, assessing for breastfeeding dysfunction, and implementing interventions if feeding dysfunction is present. The algorithms contain interventions specific to trisomy 21 , congenital heart defects, and oral cleft defects.

\section{Significance}

Healthy People 2020 identifies twelve leading health indicators (LHI) which are high-priority concerns to be addressed to improve health for everyone within the United States of America (US Department of Health and Human Services...Healthy People 2020, 2018). LHI number five is Maternal, Infant, and Child Health. In addition, the US Department of Health and Human Services has an Office on Women's Health with an online presence, which promotes breastfeeding as beneficial to society because breastfeeding saves infants' lives, saves money, increases workforce productivity (through less missed days to care for a sick infant), and is better for the environment (US Department of Human Services, Office on Women's Health, 2018; Binns, 2016). It is estimated that if $90 \%$ of infants in the US were exclusively breastfed for six months as recommended, over 900 infant deaths per year would be prevented (Bartick and Reinhold, 2010). Infants with health deviations are known to be breastfed less than healthy infants (Spatz, 2011). This doctoral project contributes to improving health in the United States by supporting and promoting breastfeeding, particularly for infants with health deviations. 


\section{Research Question}

The research question which arises from my area of interest is:

What are registered nurses' views regarding the perceived strengths, weaknesses, and overall functionality of pictorial algorithm training taught through role play for assessing feeding dysfunction and supporting breastfeeding for infants with common congenital anomalies and defects?

To quantify the learning value of the teaching algorithms using role play and peer check-off, an additional research question will be:

Does breastfeeding knowledge of registered nurses increase after receiving training using pictorial algorithms, role play, and peer check-off for teaching breastfeeding, assessing for feeding dysfunction, and supporting breastfeeding for infants with common congenital anomalies and defects?

\section{Conceptual Framework}

Teaching and learning during the focus groups was done through role play and peer check-off. Mduma et al., (2018) found simulation, especially when used in frequent short training sessions, is effective in training perinatal healthcare personnel. Bandura's social learning theory and its emphasis on self-efficacy support these methods.

\section{Bandura's Social Learning Theory}

Albert Bandura developed social learning theory in 1977 and has continued to create and hone his theory (Braugnart and Braugnart, 2018, p. 217). Bandura accepted Pavlovian conditioning and Skinner's operant conditioning theories; however, he saw the behaviorists' understanding of stimulus and response as limited, missing the bridge between the two steps. He developed his theory to 
explain how a person learns, that is, how they connect the stimulus to the response (McLeod, 2016).

Bandura's recent work focuses on self-efficacy, both self-efficacy expectations and outcome expectations. Self-efficacy expectations refer to an individual's beliefs about being able to complete a task or learn a new behavior. Outcome expectations are what the individual expects to happen if she/he succeeds or fails at learning the new task. An individual can believe a behavior is valuable and will produce a desired outcome, but not believe he or she is capable of learning or accomplishing that behavior. Likewise, someone may be confident in his/her ability to perform a task but not care to spend the time required to learn and complete the task because the outcome is not deemed important (Resnick, 2008).

A nurse teaching breastfeeding must believe she can adequately teach and that the mother can successfully learn. The nurse must also value the outcome of increased breastfeeding in order to commit the time and effort to performing the teaching. If the infant has an anomaly which makes breastfeeding difficult, the nurse and the mother might doubt the ability for successful breastfeeding and not consider the teaching and learning efforts worth the potential benefits.

Triadic reciprocality: Person, behavior, and environment. Bandura described the relationship between the theoretical constructs of person, behavior, and environment as triadic reciprocality (Braugnart and Braugnart, 2018, p. 183). Each construct influences the others and is influenced by the others in return. Bandura emphasized that the three constructs may not be weighted equally in the influence they exert. This doctoral project analyzed the strengths, weaknesses, and overall usefulness of a breastfeeding training program designed particularly for 
infants with common congenital anomalies and defects. In this study, the person is the perinatal nurse receiving the training; the behavior is the ability to teach, assess, and support breastfeeding; the environment includes the presence of a congenital anomaly which is anticipated to impact negatively the infant's ability to breastfeed. The three factors will each affect the others, but the strength of the effects will vary significantly between the registered nurses in the study. It is important to recognize this interplay of concepts and design flexibility into the breastfeeding training program to adjust for the unlimited variations from different weighting, affect, and effect levels for different registered nurses in their comfort with learning the program and utilizing the program with mothers and infants.

Social learning theory. Albert Bandura began teaching at Stanford University in 1953. As a professor of psychology at a leading research institution, he was able to develop and test his theory through his own research and through the research of his graduate students (Foster, 2006). Bandura's most famous experiments to test and demonstrate social learning theory are the Bobo doll studies of the early 1960's, in which various levels of aggressive behavior toward the doll were modeled, and then imitated, by preschool children, documenting that learning can occur through modeling and imitating (Braungart and Braungart, 2018).

Bandura's theories have been applied to many disciplines including psychology (where they were developed), education, medicine, and even breastfeeding. Awano and Shimada (2010) applied Bandura's concept of selfefficacy in a study to examine possible ways to increase breastfeeding in Japan, where rates have decreased in recent years. Ansari, Abedi, Hasanpoor, and Bani (2014) completed a similar study in Iran by providing breastfeeding education to a 
study group of pregnant women who intended to breastfeed. They found significantly longer breastfeeding among the experimental group who received the education compared to the control group who did not.

Bandura's theory and this project. Bandura's concepts of self-efficacy expectations and outcome expectations as well as learning through modeling fit this doctoral project. Healthcare workers and mothers of infants with congenital defects and anomalies need to believe infants with congenital anomalies and defects can breastfeed. They also need to value the increased nutrition, bonding, and immunity provided through breastfeeding, making the effort of teaching and learning breastfeeding worth the time and effort. This doctoral project tested algorithms designed to improve self-efficacy expectations of healthcare personnel to effectively teach breastfeeding to mothers of infants with defects and anomalies. By using simple teaching algorithms rather than complex material, registered nurses might believe the benefits outweigh the difficulty of teaching and supporting breastfeeding for infants with feeding difficulties.

Social learning theory supports training registered nurses using role play and peer check-off. In this study, registered nurses will receive training on the algorithms in a group setting where learning can be increased through watching each other. Their opportunities to learn through observing and modeling increase by using objective structured clinical evaluations (OSCEs) to check each other off.

\section{Helping Babies Survive}

In 2010 the AAP developed Helping Babies Breathe (HBB) in a collaborative effort with the U.S. Agency for International Development (USAID), Leardal Corporation, and other non-government organization (NGO) supporters to decrease infant mortality in countries with the highest levels of stillborn births and 
neonatal deaths. After the remarkable results of HBB, two additional training courses were launched: Essential Care for Every Baby in 2014 and Essential Care for Small Babies in 2015 (AAP, 2018). Together, the three courses comprise Helping Babies Survive. These courses are taught using simple green-yellow-red algorithms and low-fidelity simulation (role playing). Learning is assessed by objective structured clinical examination (OSCE) tools. HBB teaches to dry, warm, and assess breathing on every baby during the first minute of life, which is labeled "the golden minute." Babies who are not breathing are treated according to the algorithm with basic interventions including stimulation, clearing the mouth and nose, and escalating to providing breaths if needed.

Essential Care for Every Baby outlines assessments and interventions during the first 24 hours of life including kangaroo care, monitoring temperature, early initiation of breastfeeding, and teaching the mother how to hand express breastmilk to encourage latching-on. Essential Care for Small Babies focuses on anticipated needs of small or preterm infants including warmth through skin-toskin and wrapping, and possible alternative methods for nutrition such as nasogastric feeding. Helping Babies Survive is evidence-based. The AAP maintains records of Helping Babies Survive courses which have been taught and statistics on neonatal mortality in the communities which have received the training. These statistics can be found on their website (AAP, 2018).

The Helping Babies Survive training material is designed with greenyellow-red columns. This doctoral project utilizes the same visual format. The algorithms for this project begin with teaching basic breastfeeding positions while assessing if the infant is receiving adequate breastmilk, through observing for swallowing and counting wet and dirty diapers. If the outcomes are met, the nurse 
instructs the mother to continue with the current breastfeeding strategies. If the outcomes are not met, the nurse teaches new breastfeeding techniques from the yellow column and continues to observe for the desired outcomes. If the outcomes are still not met, the nurse moves to the final column which includes hand (or mechanical, if available) expression of breastmilk and alternative feeding methods such as bottle, cup, or tube feeding of the expressed milk. The goal is to find the breastfeeding technique that is most effective for the baby given the congenital defect or anomaly. At each level of the algorithm, the nurse encourages the mother--promoting self-efficacy expectations, and reminds her of the benefits of breastmilk--maintaining outcome expectations.

The simple pictorial algorithms are multifunctional. They are used to train perinatal nurses to support breastfeeding. They can also be used by the perinatal nurse to teach and support the new mother. Finally, these algorithms can be quickly and easily reviewed by the perinatal nurse, offering low-dose, highfrequency training. Mduma, Ersdal, Svensen, Kidanto, Auestad, and Perlman, (2018) found when perinatal healthcare providers received frequent review-referred to as low-dose high-frequency training--of neonatal resuscitation, neonatal mortality rates improved.

By applying Bandura's social learning theory through role play and peer check-off, this doctoral project seeks to increase registered nurses' self-efficacy expectations regarding teaching breastfeeding to mothers of infants with feeding difficulty. Outcome expectations for both the new mothers of infants with anomalies and the registered nurses will increase by showing ways to overcome feeding difficulties, making the benefits more easily achieved. 


\section{CHAPTER 2: LITERATURE REVIEW}

Before effective training and support can be established to increase breastfeeding rates among infants with anomalies and defects, the impediments to breastfeeding - real and perceived — must be identified. The following research articles identify reasons women stop breastfeeding sooner than they planned or desired.

\section{Reasons for Cessation of Breastfeeding}

Odom, Li, Scanlon, Perrine, and Grummer-Strawn (2013) completed a longitudinal study to identify reasons mothers discontinued breastfeeding earlier than they wanted. The study included 1,177 mothers. There were 2,572 mothers considered for the study, but mothers who did not answer pertinent questions were excluded. The data was obtained from the Infant Feeding Practices Study II (IFPS II) conducted from across the USA by the US Food and Drug Administration and the Centers for Disease Control and Prevention between 2005 and 2007. To qualify for the IFPSII, the mother had to be at least 18 years old with a single birth

over 35 weeks gestation and greater than 5 pounds without any medical conditions which could interfere with breastfeeding. Mothers were given a questionnaire to fill out during their third trimester and then monthly after the birth of their baby until the baby was one year old.

The outcome measures that Odom et al. (2013) studied were whether or not the mother breast fed as long as she wanted, correlated with the reasons for stopping. Multiple logistic regressions were run to examine the importance of 32 potential reasons for stopping breastfeeding earlier than desired. The mothers identified the strength of each reason using a 5-point Likert scale. Study findings showed health concerns (infant nutritional concerns perceived or actual, maternal 
illness or need for medication, and infant illness) and processes associated with breastfeeding (poor suck, painful breastfeeding) were the primary reasons mothers discontinued breastfeeding before they wanted. These reasons to stop breastfeeding correlated at a statistically significant level to stopping breastfeeding sooner than the mother wanted. This is a strong study because of the large subject size and careful selection process done by the IFPS II. Demographic data of the mothers was carefully identified and assessed. One weakness is mothers who received lactation consultation were not separated from those who did not. This study is helpful to identify reasons mothers stop breastfeeding sooner than they want, but does not identify interventions to prolong breastfeeding.

Another longitudinal study which utilized the IFPS II data was conducted by Stuebe, Horton, Chetwynd, Watkins, Grewen, and Metzer-Brody (2014) correlating undesired weaning with maternal body mass index (BMI) and postpartum depression scores. Of the 4,902 women enrolled in IFPS II, 2,235 reported the scores utilized in this study and therefore were included in the statistical analyses. Stuebe et al. (2014) considered interrupted lactation to be mothers who identified at least two of the following three reasons to stop breastfeeding earlier than desired: breast pain, low milk supply, and/or difficulty with latch.

Demographic data for the mothers with interrupted lactation showed they were more likely to be young, Hispanic, unmarried, nulliparous, not have a college degree, and receive assistance through the supplemental nutrition program Women, Infants, and Children (WIC). Logistic regression found statistically significant associations between maternal body mass index, postpartum depression scores, and interrupted lactation with an increased odds ratio of 1.7 with 95\% confidence for both obesity and maternal depressive score at 2 months. One 
strength of this study is the large, diverse sample provided by IFPS II and the use of a well-respected and normed test for post-partum depression scores. The study authors identify a weakness of their study as not being able to separate physiologic factors from psychologic or perceived dysfunction leading to undesired weaning.

Rather than identifying reasons women stopped breastfeeding, Augustin, Donovan, Lozano, Massucci, and Wohlgemuth (2014) conducted a survey to identify factors common among mothers who were still breastfeeding at six months. They sent an anonymous, descriptive, 20-question survey via Survey Monkey $\odot$ to 806 mothers six months after delivering at a suburban community hospital. The response rate was $50 \%$. Of the respondents, $69 \%$ were still breastfeeding at six months. While this was a convenience sample, the authors assessed demographic data and found the study group to be relatively homogeneous in age, socioeconomic status, educational level, and location of suburban living. Qualitatively they asked for the mothers' experiences with breastfeeding as well as basic care experienced at the hospital. What they discovered was among the women who continued to breastfeed at six months, $62 \%$ had immediate skin-to-skin contact with their baby, $85 \%$ had a partner who was supportive of breastfeeding, and $70 \%$ of the infants did not receive formula in the hospital. A surprising find was only $29 \%$ of the women who were still breastfeeding at six months had participated in prenatal breastfeeding education; however, the primary reason (given by $61 \%$ ) was previous experience with breastfeeding.

Several factors emerged from this study as recommendations which may promote higher breastfeeding rates. They include immediate skin-to-skin, providing breastfeeding support education to partners, and not offering infant formula in the hospital unless medically necessary. Another recommendation is to 
do further study to understand why women do not receive prenatal breastfeeding education and how to provide effective breastfeeding support education to partners.

This study had a good response rate at 50\% and limited the scope to a homogeneous group of women. Weaknesses of this study include the large number of subjects which dilutes the qualitative data with too many experiences. Another weakness is the study did not differentiate between exclusive and partial breastfeeding.

Bonuck, Stuebe, Barnett, Labbok, Fletcher, and Bernstein (2014) conducted a single-blind, randomized, control study in Bronx, New York comparing breastfeeding duration between study groups receiving differing amounts of breastfeeding education. Subjects received care at an urban obstetrics and gynecology practice between 2008 and 2011. Subjects were recruited during their prenatal visits. Subjects had to speak either English or Spanish, be over 18 years of age, in their first or second trimester, having a single birth, have no risk factors for prematurity or other complications for breastfeeding. The 666 women included in the study were randomized into either usual care, electronic prompting only (EP), lactation consultant only (LC), or EP and LC. The outcomes assessed through phone interviews were infant feeding at 1, 3, and 6 months postpartum.

Women in the usual care group did not receive any special breastfeeding education; however, lactation consultants were routinely present in the office during prenatal visits and available to all of the subjects. In the EP group, the primary provider was electronically prompted at five prenatal visits to ask two or three brief open-ended questions about breastfeeding. The LC group received two prenatal sessions with a lactation consultant and one postpartum session during the 
infant's one week visit to the pediatrician. The EP plus LC group received both the prompted queries and the lactation consultations.

Based on the large number of possible pair-wise comparisons a large sample was needed, so 666 women were enrolled in the study. Chi square or Fisher exact tests were done for categorical variables and analysis of variance was run on continuous variables. The study found that breastfeeding rates differed between the treatment groups at one and three months. The group with EP plus LC had the highest levels of breastfeeding. The group with LC only was very close but not quite at a statistically significant level for increased breastfeeding over the control group. The group with EP only was not statistically different than the control group. Therefore, the findings show that multiple interventions from the primary provider and a lactation consultant provide the best chance of increasing breastfeeding duration and intensity.

This was a well-conducted study with randomized study groups. The sample size was large. Also, the retention rate was $95 \%$ which is more than in similar studies. Self-report data is always potentially biased, and therefore a weakness for this study. Women in this study self-reported whether or not and how much they were breastfeeding at 1 month, 3 months, and 6 months. Another weakness in the study design was that women received the interventions at set times, as opposed to being able to access help when they felt they needed it.

Since women who qualify for WIC have a lower rate of breastfeeding, Harari et al. (2017) conducted a qualitative/quantitative study to assess the feasibility and acceptability of text message interventions from a peer counsellor to breastfeeding WIC recipients. The study was conducted through a satisfaction survey. Participants between 20 to 38 years of age were enrolled during the middle of their pregnancy from two WIC breastfeeding peer counselling programs in one 
medium sized city. Thirty mothers were assigned to the texting intervention group and 22 were assigned the control group with a peer counselor without texting. The outcome goals of this study were to determine if utilizing text messages between new mothers and peer counselors was feasible and if the new mothers would find it acceptable to receive breastfeeding information by text.

The study found that contact between the mother and her peer counselor within 48 hours of giving birth was higher for the text message group, demonstrating feasibility. Also, all of the women enrolled in the experimental group who completed the survey were highly satisfied and would recommend text messaging peer counseling for breastfeeding to their friends. This study found exclusive breastfeeding at two weeks was higher in the text message group compared to the control group, but not at a statistically significant level. A strength of this study is it was a well-controlled mixed methods study to assess feasibility and acceptability, using a small sample size of similar subjects. It sets the stage for a larger quantitative study to evaluate the effectiveness of text messaging through peer counselors for breastfeeding. A weakness is the sample was too small to evaluate effectiveness of text messaging through peer counselors on breastfeeding.

\section{Breastfeeding Infants with Congenital Defects and Anomalies}

Infants with congenital defects and anomalies are at risk of receiving minimal or no breastmilk (Worrall, 2007). The following articles studied breastfeeding and/or breastmilk provision to infants with congenital defects.

Barbas and Kelleher (2004) studied breastfeeding among infants with congenital heart defects. They conducted a qualitative and quantitative survey, sending out questionnaires on two occasions to mothers of infants at least six 
months old with congenital heart disease (CHD) who required surgery during the first month of life. They identified 106 mother-infant dyads who met the inclusion criteria and received responses from 68 mothers for one questionnaire and 61 mothers for both questionnaires. Their research was designed to qualitatively describe duration and outcome of breastfeeding among high-risk infants with $\mathrm{CHD}$, and quantitatively compare current rates and intensity of breastfeeding to a similar study done in 1993.

Mothers in the study ranged from 18 to greater than 36 years of age with high school to advanced degree education; however, the majority of the subjects fell within 31-35 years of age and had an undergraduate degree. All of the infants in the study received heart surgery at Children's Hospital of Boston between July 1998 and April 2000. The infants received breastmilk while in the hospital, plus the mothers received breastfeeding education and a breast pump prior to discharge. The study questionnaires asked mothers about using the breast pump at the hospital and their initiation of breastfeeding including frequency and duration after discharge.

The qualitative responses in the survey showed the mothers received mixed messages from providers after surgery. Many infants were offered a bottle before the mother was allowed to breastfeed. Some mothers even received the impression that formula was better for the baby. The post-discharge findings showed over $80 \%$ of the infants received at least some breastmilk at three months of age and 65\% at five months. This is a significant increase at both ages from the 1993 study. The study attributes the high post-discharge breastfeeding to lactation education, including pumping and transitioning to breast. The study also notes the need for providers to promote breastfeeding for infants with CHD post-surgery. Strengths of this study are the high response rate for a survey (64\%) and the 
informative qualitative information about mothers' perceptions of providers attitudes toward breastfeeding infants with CHD. Limitations include subjects coming from a single hospital.

Martino, Wagner, Froh, Hanon and Spatz (2015) studied breastfeeding among infants who received surgery for complex anomalies. They conducted a prospective cohort study to examine the duration and exclusivity of breastfeeding post-discharge for infants who received care in the neonatal intensive care unit (NICU) and underwent surgery. Their study included 165 infants. The infants received care at The Children's Hospital of Philadelphia between 2009 and 2012. Data was collected through telephone interviews and analyzed with descriptive statistics. The average length of receiving breastmilk among their subjects was eight months. At six months $60.1 \%$ were receiving breastmilk and at 12 months $34.5 \%$ were receiving breastmilk. These statistics are higher than the state and national averages for all infants regardless of health conditions. The study differentiated how breastmilk was provided at discharge: feeding at the breast (30\%), bottle feeding expressed milk (59\%), and tube feeding (30.7\%). During the first year of life over $40 \%$ of the infants feed at the breast for at least some of their feedings.

Children's Hospital of Philadelphia has a strong breastfeeding emphasis and offers training to all staff to promote breastmilk and breastfeeding. This study supports the efficacy of developing an organizational culture of promoting breastfeeding and breastmilk. One strength of this study is the large sample size, but a limitation is the sample was relatively homogeneous. The majority of the mothers who participated identified themselves as white and the mean age of the mothers when giving birth was 30 years. 
Burianova, Kulihova, Vitkova, and Janota (2017) completed a retrospective cohort study to assess breastfeeding rates of infants with cleft lip compared to cleft lip and palate among infants who underwent early corrective surgery. There was no prior data available for comparison of rates of breastfeeding among infants with cleft lip or cleft lip and palate. The study was conducted in the Czech Republic in a baby-friendly hospital where breastfeeding is treated as normal and support is readily available. One hundred four infants were included in their research: 56 with cleft lip only and 28 with cleft lip and palate. Infants in the study had to be over 34 weeks gestation and at least 2000 grams. All infants were breastfeeding prior to surgery, and receiving care from a special breastfeeding support team. The infants underwent surgery between one and thirteen days of life.

Quantitative statistics were done using t-tests for normally distributed variables and Mann-Whitney nonparametric tests for variables without normal distribution. Findings showed $78.6 \%$ of the infants with cleft lip were breastfeeding at the time of hospital discharge. This is similar to the general rates of breastfeeding in the Czech Republic. Among the infants with cleft lip and palate, $6.2 \%$ were breastfeeding at discharge and an additional $64.6 \%$ were receiving breastmilk from a bottle or specially designed cleft palate bottle.

Complications from surgery were minimal and outcome results were good after early surgery. Results of this study indicate infants with cleft lip who undergo surgery within the first two weeks of life can breastfeed successfully even with the disruption of skin-to-skin and post-surgical pain. It also demonstrated significantly lower breastfeeding rates for infants with cleft palate. However, with breastfeeding support, a majority of mothers of infants with cleft palate can produce adequate milk to provide breastmilk through an alternative feeding method. One strength of this study was a good sample size with clear inclusion criteria. A weakness was 
they were not able to compare early surgical repair to later surgical repair since their hospital has performed only early repair since 2005 .

Infants with trisomy 21, also called Down syndrome, have lower rates of exclusive breastfeeding (Magenis, Machado, Bongiolo, Silva, Castro, and Perry, 2018), likely due to facial structural anomalies and decreased muscle tone. A literature review conducted in the United Kingdom attempted to identify breastfeeding prevalence and factors influencing breastfeeding among infants with trisomy 21 (Sooben, 2012). Sooben searched for studies in English and found seven studies on breastfeeding infants with Down syndrome conducted between 1983-2009. The studies were completed in various countries, with only one study done in the UK. In the literature review, data was grouped and analyzed in three categories. The categories were feeding problems/feeding habits, mothers' breastfeeding decision, and impact on the health of the infant. Results for feeding problems/feeding habits included later initiation of solids for infants with Down syndrome which might be a contributing factor to delayed speech development, and maternal feelings of anger and shock which may influence breastfeeding and prompted the recommendation for increased emotional support. The mothers' breastfeeding decision showed that infants who had Down syndrome and were separated from the mother after birth had decreased breastfeeding rates. In the same study it was noted that infants in the NICU who did not have Down syndrome were more likely to be breastfed than the infants with Down syndrome. The literature review showed the primary reasons mothers decided not to breastfeed their infants with Down syndrome was other associated medical issues such as heart defects, low birth weight, or gastrointestinal issues.

Children with Down syndrome have an increased risk for certain diseases including leukemia (American Cancer Society, no date). Literature was included 
comparing the rates of breastfeeding during infancy for children with Down syndrome who developed leukemia and those who did not. It showed infants with Down syndrome who were breastfeed for six months were less likely to develop leukemia than those who were not breastfeed as long. This literature review pulled together comprehensive information about breastfeeding among infants with Down syndrome. A weakness of this literature review is that the included studies come from seven different countries and cover a time span of over twenty-five years.

\section{Teaching Through Simulation/Role Play}

Simulation has become a standard part of healthcare training and has been shown to be an effective piece of nursing education (Lavoie and Clarke, 2017). This includes both high-fidelity simulations performed on life-like manikins and low-fidelity simulation through role play. As Dr. Gaba said during the early growth of simulation in healthcare, "Simulation is a technique - not a technology" (Gaba, 2007).

Studies have shown simulation to be effective in training nurses. Johnston, Coyer, and Nash (2018) completed a systematic review of studies on simulation in nursing education and found simulation to be an effective way to meet learning outcomes. They utilized Kirkpatrick's framework of the four levels of learning: reaction, learning, behavior, and results. Inclusion criteria was studies conducted in English between 2000 and 2016 which described debriefing interventions after conducting simulation. They began with over 1,000 potential articles. Only 13 met their inclusion criteria and were utilized in their review. In general, they found a scarcity of high-quality studies. Due to differing methodologies of the studies in their analysis, they compiled a narrative summary of their findings. Each study 
they included used a convenience sample, the smallest being 30 and the largest being 238. Subjects ranged from undergraduate nursing students to medical students and practicing healthcare providers. All studies included debriefing after simulation. Debriefing methods included video, discussion, written documentation, and journaling.

Results were categorized into the four levels of Kirkpatrick's framework. Level 1, reactions, found participants slightly preferred discussion over writing or blogging their debrief reactions. Level 2, learning, documented significant increases of learning on pre- to posttest and skills performances. Level 3, behavior, would indicate participants changed their behavior outside of the learning environment based on what they learned. This was not studied in the articles they included except with undergraduate nursing students where instructors did not see a significant change. Level 4, results, would correlate patient outcomes with provider training through simulation. None of the included articles studied this. This meta-analysis documents that simulation is effective in teaching skills and knowledge to healthcare workers, but it also highlights the need for more research on simulation.

Sutton et al. (2011) conducted a randomized control-group study to see if low-dose high-frequency (LDHF) CPR training would improve skill retention. They randomly assigned $89 \mathrm{CPR}$-trained hospital-based healthcare providers to one of four groups. Three groups received ongoing LDHF training at $0,1,3$, and 6 months. The control group did not receive any additional training. Each additional training lasted four minutes. The experimental groups included instructor-only training, automated defibrillator feedback only, and both instructor and automatic defibrillator feedback. During a simulated cardiac arrest, the study groups were compared using odds rations for effective CPR with adequate compression depth 
and rate. The experimental groups were 2.9 times more likely to perform excellent $\mathrm{CPR}$ than the control group with a $\mathrm{p}$ value of 0.005 . LDHF training appears to be an effective way to retain CPR skills.

Willcox et al. (2017) applied LDHF training with a role play-based curriculum to neonatal outcomes in Ghana. The cost of training was compared to the status quo of no training and the number of lives saved as well as disabilityadjusted life years (DALYs) prevented. Forty healthcare facilities were included in the study over a three-year period from 2014 to 2017. Inclusion criteria was public and mission hospitals where at least 30 babies were delivered per month and at least three trained birth attendants were on staff. An existing two-week conference on basic emergency obstetric and newborn care was redesigned into two, four-day trainings done at the hospital. Then, the training was reinforced through phone calls and text message reminders from a mentor trainer, along with quizzes and practice on the simulated equipment. Costs were divided up into development of the program, start up (training the mentors), and implementation which included the training and follow up. Total training costs for the 40 facilities was $\$ 823,134$. During the first year after the training an estimated 544 lives were saved. This averages to $\$ 1497.77$ per life saved or $\$ 53.07$ per DALY. Based on these costs, LDHF neonatal emergency care training is cost-effective and reasonable for Ghana.

\section{Literature Review Conclusions}

The benefits of breastfeeding are well documented and widely accepted. The CDC maintains breastfeeding rates by location. This data documents that women do not breastfeed as long as recommended. CDC statistics also identify the population most at risk for never breastfeeding or minimal breastfeeding is women 
in low-income, low-educational level communities, with a younger age at motherhood. WIC completed a pilot study and is performing a large-scale study to try new and innovative ways using cell phone texting to encourage breastfeeding among their low-income clients (Harari et al., 2017). Additional studies and creative interventions need to be employed for this at-risk population.

Multiple studies show that among women who breastfeed, most stop earlier than they had planned. Some studies have looked at the reasons women give for stopping breastfeeding early. Other studies have compared women who breastfeed exclusively for six months to those who do not, trying to identify differences. Based on study results and international trends, the WHO and United Nations Children's Fund (UNICEF) developed the Baby Friendly Hospital Initiative in 1991 (WHO, Baby-friendly Hospital Initiative, 2018). Hospitals can apply for 'Baby Friendly' status which promotes breastfeeding through immediate skin-toskin contact, early initiation of breastfeeding, and lactation support services (Baby-Friendly USA, 2018).

Another population with suboptimal breastfeeding rates is infants with common congenital anomalies and defects. The literature shows these babies tolerate breastmilk well when given via alternative feeding methods. As their health stabilizes or improves, many of these babies can successfully transition to receiving part or all of their nourishment at the breast. However, healthcare providers often do not encourage, or may even show resistance toward, breastfeeding for infants with anomalies and defects.

\section{Gaps in the Literature}

Exclusive breastfeeding for six months is recommended, but in the United States new mothers are not meeting this recommendation. Most current 
breastfeeding research focuses on identifying causes for the mismatch between the recommendation and actual practice. Some studies have retrospectively identified differences immediately after birth between mothers who breastfeed successfully and those who stopped early. Other research has attempted to improve breastfeeding length and duration with various interventions such as more exposure to lactation consultants and/or texting and messaging. Still other studies look at materials to aid breastfeeding mothers. In all of these studies, new mothers are the subjects.

My project was designed to train registered nurses, and registered nurses are the subjects. This makes my project practical and fills a gap in the literature. In local hospitals, lactation consultants work with new mothers to teach and support breastfeeding. The labor and postpartum registered nurses have some knowledge of breastfeeding but refer clients to the lactation consultants if feeding difficulties are present or suspected. Pediatric and NICU nurses may have little to no training in supporting breastfeeding. My algorithms are designed for the registered nurses caring for the mother and infant shortly after birth, rather than for new mothers or for lactation consultants. 


\section{CHAPTER 3: METHODOLOGY}

\section{Method}

This project is a mixed methods pilot study utilizing two focus groups. The qualitative portion of this study is a conventional content analysis. The original design called for summative content analysis with coding and counting responses from a guided discussion (Hsieh and Shannon, 2005). However, during the focus groups it quickly became apparent there was a lot of nonverbal information that could not be captured and counted on a word-for-word transcription. Instead of relying on counting, the content analysis was conducted by coding comments during the guided discussion as facilitators and barriers.

The quantitative portion is a cohort study analyzing the difference in breastfeeding knowledge before and after the training using a pre- and posttest. Descriptive statistics were run to describe the subjects' age, gender, years as a registered nurse, highest degree in nursing, and areas of nursing experience. (See Appendix E for the demographic data questionnaire.) All subjects were registered nurses living in or near Fresno, California who willingly participated in a focus group on supporting breastfeeding.

\section{Sample and Subject Confidentiality}

This research was conducted with two separate focus groups. The first focus group was recruited through snowball sampling. As a pediatric nurse educator, I am acquainted with many perinatal registered nurses. I invited registered nurses I know to invite registered nurses they know to participate in the focus group. A flyer with the time and location of the focus group and my contact information in case of questions was provided to nurses I know. They were encouraged to hand it out to nurses they know. The fliers were not posted in any 
facility, but were shared with registered nurses in multiple healthcare organizations. Participation was voluntary. Quite a few registered nurses expressed interest in participating, however only four registered nurses attended the snowball focus group. The snowball group had one new nurse with less than a year of experience while the other nurses all had greater than 10 years of experience. All four were female.

The second focus group consisted of 15 registered nurses who work or volunteer at Pregnancy Care Center (PCC) in Fresno, California. Demographically, the PCC registered nurses varied in age and nursing experience, but they were all female. They also share a pro-life bias and choose to work or volunteer at a faith-based facility.

Quarterly, PCC holds a medical update meeting for the registered nurses. The fall medical meeting was slated for my data collection. In order to ensure ethical research and autonomy, the registered nurses were informed before the meeting about the research and participation was voluntary. If a nurse had come and then declined to participate, the information would not have been shared with administrators or staff at PCC. Fifteen registered nurses attended the medical meeting and all 15 chose to participate.

This research project was reviewed and approved by the California State University, Fresno Institutional Review Board and found to pose minimal risk to subjects (see Appendix G). In the unlikely event that a subject experienced emotional discomfort from participating in a focus group, a counselor at PCC was designated as the referral resource. To maintain confidentiality, registered nurses who participated in a focus group were assigned a random number for identification. At the beginning of the focus group, each nurse was given a packet containing a demographic form, breastfeeding knowledge pretest, objective 
structured clinical exams (OSCEs), discussion question prompts, and breastfeeding knowledge posttest. Each form had the random number for that nurse on it. Registered nurses also signed a consent form before they participated, but the consent form did not have their random number attached to it. The random number was not connected to their name and their name was not connected to their information or results.

\section{Inclusion and Exclusion Criteria}

The established inclusion criteria was registered nurses who attended one of the focus groups. Exclusion criteria for the PCC focus group was set as any registered nurse who did not work at PCC and exclusion criteria for both groups was any individual who was not a registered nurse. All potential subjects who came to one of the focus groups were included; no exclusions were necessary.

\section{Capability to Provide Informed Consent}

All subjects were registered nurses. As such, they were competent adults and capable of signing an informed consent, including understanding their right to not participate.

\section{Setting}

The PCC focus group took place at Pregnancy Care Center on Olive Avenue in Fresno. PCC is a small facility with a flat organizational structure, which simplified the approval process for my project. The nurse manager is on my project committee and approved my research to be conducted at the center. The nurse manager reports to the medical director and the board of trustees and kept them informed of my research project. A letter approving the site for my research is attached. (See appendix H.). PCC did not require a formal IRB process since I did not interact with clients, nor review clients' charts. 
The location for the snowball sampling group was a church social hall in Kingsburg, California which offers a free meeting room for community events. The church is well known for allowing organizations such as Boy Scouts and Cancer Volunteers to use its facility.

\section{Data Collection}

Qualitative data was collected to receive feedback from registered nurses about the strengths, weaknesses, and overall functionality of the breastfeeding teaching algorithms and breastfeeding support training program. At the end of each focus group a guided discussion was audio recorded (refer to focus group questions in appendix E). The recordings were transcribed word-for-word without identifying speakers. The anonymous transcriptions were shared with the research project committee members and analyzed through content analysis using the computer program NVivo for coding and word count. A breastfeeding knowledge pre- and posttest was administered to quantitatively measure the group's level of breastfeeding knowledge before the training compared to after the training (see breastfeeding knowledge pre- and posttest in appendix C). Additionally, demographic data of the registered nurses in the focus groups was obtained (Appendix B). Descriptive demographic data and paired t-tests of breastfeeding knowledge pre- and posttest scores were run using SPSS.

\section{Data Collection Process}

Data collection began with the breastfeeding knowledge pretest and demographic data sheet. Then, the facilitator conducted an approximately 15minute training to demonstrate use of the first breastfeeding algorithm which teaches breastfeeding positions and interventions for common breastfeeding complaints. Participants were given time to practice implementing the algorithm 
on each other using role play. Next, they checked each other off based on the OSCE. When check offs were done, the algorithm for supporting breastfeeding among infants with a common congenital anomaly or defect was demonstrated. Practice and check off followed. After the teaching and check-offs were completed, the registered nurses were led through a guided discussion using the discussion prompts in Appendix E. The discussions were audio recorded. Finally, the participants completed the breastfeeding knowledge post-test. After the focus groups were completed, the audio recordings were transcribed word-for-word and used for coding and analysis.

During the teaching demonstration portions of the focus groups, the facilitator obtained a volunteer from the participants and demonstrated use of the breastfeeding training algorithms. The facilitator role played being a perinatal nurse and taught breastfeeding to the participant who role played being a brandnew mother. A life-sized doll was used in the role playing as the infant. After observing the training demonstration, the registered nurses divided into small groups of two or three and practiced applying the algorithm. One participant role played being a new mother shortly after delivering her "baby" which was the lifesize baby doll. Another participant was the "nurse" and taught the "mother" about breastfeeding. The "nurse" guided the "mother" and "baby" through five recommended breastfeeding positions. The "nurse" verbalized what she was observing to assess for adequacy and safety of breastfeeding. After each participant practiced being the "nurse" they checked off each other using the OSCE. A few groups had three participants, so the individual not role playing evaluated the competency of the "nurse" based on the OSCEs. In groups of two participants, the "mother" followed along on the OSCE and checked off the "nurse." The participants alternated roles until each person had passed the OSCE. 
In the same way, the algorithm for supporting breastfeeding of an infant with a common congenital anomaly or defect was demonstrated, practiced, and checked off. Participants observed the demonstration, role played assessing the "infant," and recommended interventions to improve breastfeeding. They traded roles while they practiced and checked off with the OSCE.

\section{Frequency and Duration}

Subjects participated in one focus group lasting two hours. The two focus groups were conducted one day apart — on Sunday and Monday — to minimize the possibility of a subject from the first group discussing the research with a participant in the second group, potentially invalidating the results of the second group. Participants were not subject to any procedures beyond the focus group.

\section{Instruments}

The Mother, Infant, Young Child Nutrition and Malnutrition Knowledge Tests - Breastfeeding (see Appendix C) is available through creative commons. It may be used without obtaining permission as long as attribution is given and no changes are made (The Maternal and Child Health and Education Trust, 2018). All other instruments used during the focus groups were developed by the researcher. Pictures on the algorithms (see Appendix A) were drawn specifically for this project, except the common features of Down Syndrome (Lucina Foundation, used with permission) and oral cleft defects (Centers for Disease Control and Prevention, National Center on Birth Defects and Developmental Disabilities, 2017, public domain image), so there are no copyright violations. The demographic questionnaire (see Appendix B) and guided discussion questions (see Appendix E) are unique for this project. Prior to data collection, the researcher and committee members reviewed the questions to ensure they were meaningful. 
The Mother, Infant, Young Child Nutrition and Malnutrition Knowledge Tests - Breastfeeding was developed by The Mother and Child Health and Education Trust (MCHET). The MCHET is an extensive web-based resource promoting the health of mothers and infants globally. It contains multiple links, videos, educational information, data, and health and nutrition recommendations (The Mother and Child Health and Education Trust, 2018). The Knowledge TestsBreastfeeding is currently under development, so reliability and validity data are not yet available. However, because it is the most well-developed and appropriate test available for this study, it was chosen as the pre- and posttest to measure the difference in breastfeeding knowledge before and after the training.

\section{Data Analysis Methods}

The qualitative portion of this study was analyzed using content analysis for coding and word counting to identify the most common comments (Graneheim and Lundman, 2004). Participant comments were coded as facilitators, which helped them learn the material, and barriers, which were not helpful for learning or even interfered with learning. Breastfeeding knowledge pre- and posttest differences were measured using paired t-tests. The level for statistical significance was set at 0.05 . Descriptive statistics were used to describe the focus groups, identifying frequency and means of each item on the demographic questionnaire.

\section{Limitations}

This doctoral project is a pilot study seeking to understand registered nurses' perception of and attitude toward the breastfeeding support training program, including the algorithms and teaching/learning through role play. While a small sample size allows for richer understanding in qualitative research, it also 
limits transferability of findings. This study analyzed two focus groups for a total of 19 participants, making it subject to this limitation. This research utilized a fairly homogenous convenience sample which further limits theoretical findings and weakens study results since the subjects are not a randomized cross-section of perinatal nurses.

Another limitation of this study exists because the developer of the program led the focus groups. Participants may be reluctant to express their opinions, especially negative views, knowing the focus group facilitator developed the algorithms and materials used in the study. Additionally, the tools used in this research have not been validated. Most of the tools used in this study were designed for this study, and therefore do not have existing reliability and validity data. The breastfeeding knowledge pre- and posttest is an existing, public tool, but reliability and validity testing results are not available.

\section{Trustworthiness and Credibility}

Trustworthiness and credibility are always a potential threat to a qualitative study. To promote credibility, the guided discussion was audio recorded and transcribed word-for-word, without the speakers identified to ensure privacy and confidentiality. Then, the transcripts were coded. The transcripts and initial coding were distributed to the committee. Dialog and revision ensued. The original study design planned to have each committee member code and count independently, comparing results. However, the transcripts identify several places where murmured agreement is heard but exact numbers cannot be counted. Also, the researcher observed many instances of nodding and other nonverbal contributions to the guided discussion which do not appear on the transcripts, decreasing the effectiveness of counting for analysis. 
Basic preliminary codes were developed prior to data collection based on assumptions and the discussion prompts. (see Appendix D for open-ended discussion prompts.) As the transcripts were analyzed, the codes were changed and minimized to facilitators and barriers. Facilitators were factors subjects identified which helped them learn the material presented during the focus group. Barriers hindered their learning.

Trustworthiness was improved by including input from the committee members creating consensus coding (Hays and Singh, 2011). Stability reliability is high since this is a focus group. Attrition was not a problem since data from each subject was collected during a single encounter. Two focus groups were included in the data, but each subject attended only one. Transferability is increased by obtaining good demographic information about the registered nurses in the focus groups including age, years of nursing practice, primary area of nursing, and previous knowledge of breastfeeding (Hays and Singh, 2011).

\section{Nursing Implications}

This doctoral project has the potential to change perinatal nursing practice by changing how registered nurses are trained for supporting breastfeeding and assessing for feeding dysfunction. Simulation has become a common teaching modality in healthcare (Rosen, 2008). This project will offer a new curriculum implementing low-fidelity simulation through role play to train perinatal registered nurses to teach and to assess breastfeeding by following algorithms.

This project also has the potential to increase breastfeeding including for infants with congenital defects and anomalies. The third algorithm of the program includes intervention strategies when feeding dysfunction from a common congenital anomaly or defect is present. Martino, Wagner, Froh, Hanlon, and 
Spatz (2015) found women breastfeed longer when they receive breastfeeding support, including when the infant has an anomaly or defect making breastfeeding more difficult. This project will assist registered nurses in helping mothers of infants with defects and anomalies breastfeed, which means more breastfeeding for these infants.

\section{Next Steps}

This mixed methods pilot study was conducted as part of a doctoral program and will help to improve the algorithms and teaching strategies. The quantitative component looked at efficacy of increasing the registered nurses' breastfeeding knowledge. The qualitative component looked at the registered nurse participants' feelings about the program and recommendations for improvement. The algorithms will be edited based on the feedback from this study. Ideally in the future, the revised algorithms will be studied again, validated, and then widely disseminated. Additional studies should be conducted to assess for increased intensity and duration of breastfeeding among mothers trained by registered nurses utilizing the algorithms, particularly for infants with common congenital anomalies and defects. 


\section{CHAPTER 4: RESULTS}

Qualitative data from the two focus groups provided feedback on the effectiveness and user experience of the Breastfeeding Support Training Program. Results are described below. First, demographics of the two focus groups are listed, followed by pre- and posttest results on the breastfeeding knowledge test. Next, coding of responses during the guided discussion are detailed with the emerging themes. Lastly, considerations for improving the Breastfeeding Support Training Program based on the focus groups' feedback, researcher memos, and cumulative qualitative findings are described.

\section{Demographic Data}

A total of 19 registered nurses participated in two focus groups. The first focus group consisted of four registered nurses who were contacted through snowball sampling. The second focus group had 15 participants who all work or volunteer as registered nurses for PCC. The demographic breakdown of registered nurses participating in this study is below in Table 1. Figures 1 and 2 show the years of registered nursing experience and highest degree in bar graph format.

Table 1

Demographic Breakdown of Participating Registered Nurses

\begin{tabular}{cccc}
\hline & FOCUS GROUP 1 & FOCUS GROUP 2 & TOTAL \\
\hline AGE: & & & \\
\hline < 30 years & 1 & 1 & 2 \\
\hline $\mathbf{3 0 - 3 9}$ & 1 & 1 & 2 \\
\hline $\mathbf{4 0 - 4 9}$ & 0 & 0 & 1 \\
\hline $\mathbf{5 0 - 5 9}$ & 2 & 12 & 12 \\
\hline $\mathbf{2 6 0}$ & 0 & 15 & 19 \\
Female & & 0 & 0 \\
Male & 0 & $3.5-50$ & $0.2-50$ \\
GENDER & $0.2-31$ & $\mathrm{~m}=34.8$ & $\mathrm{~m}=29.6$ \\
YEARS OF RN & $\mathrm{m}=12.8$ & $\mathrm{sd}=12.358$ & $\mathrm{sd}=13.085$ \\
EXPERINCE & $\mathrm{sd}=15.467$ & &
\end{tabular}




\section{AREAS OF RN}

EXPERINCE:

obstetrics

NICU

pediatrics

med-surg

Other/not

specified

RN DEGREE:

\section{RN DElom}

ADN

BSN

MSN

Doctoral

$$
\begin{aligned}
& 2 \\
& 1 \\
& 0 \\
& 0 \\
& 1
\end{aligned}
$$

$\begin{array}{cc}11 & 13 \\ 4 & 5 \\ 4 & 4 \\ 10 & 10 \\ 0 & 10\end{array}$

13

5

4

10

\begin{tabular}{llll}
\hline ADN & 0 & 2 & 2 \\
\hline BSN & 2 & 2 & 4 \\
MSN & 0 & 8 & 8 \\
Doctoral & 2 & 1 & 3 \\
\hline
\end{tabular}

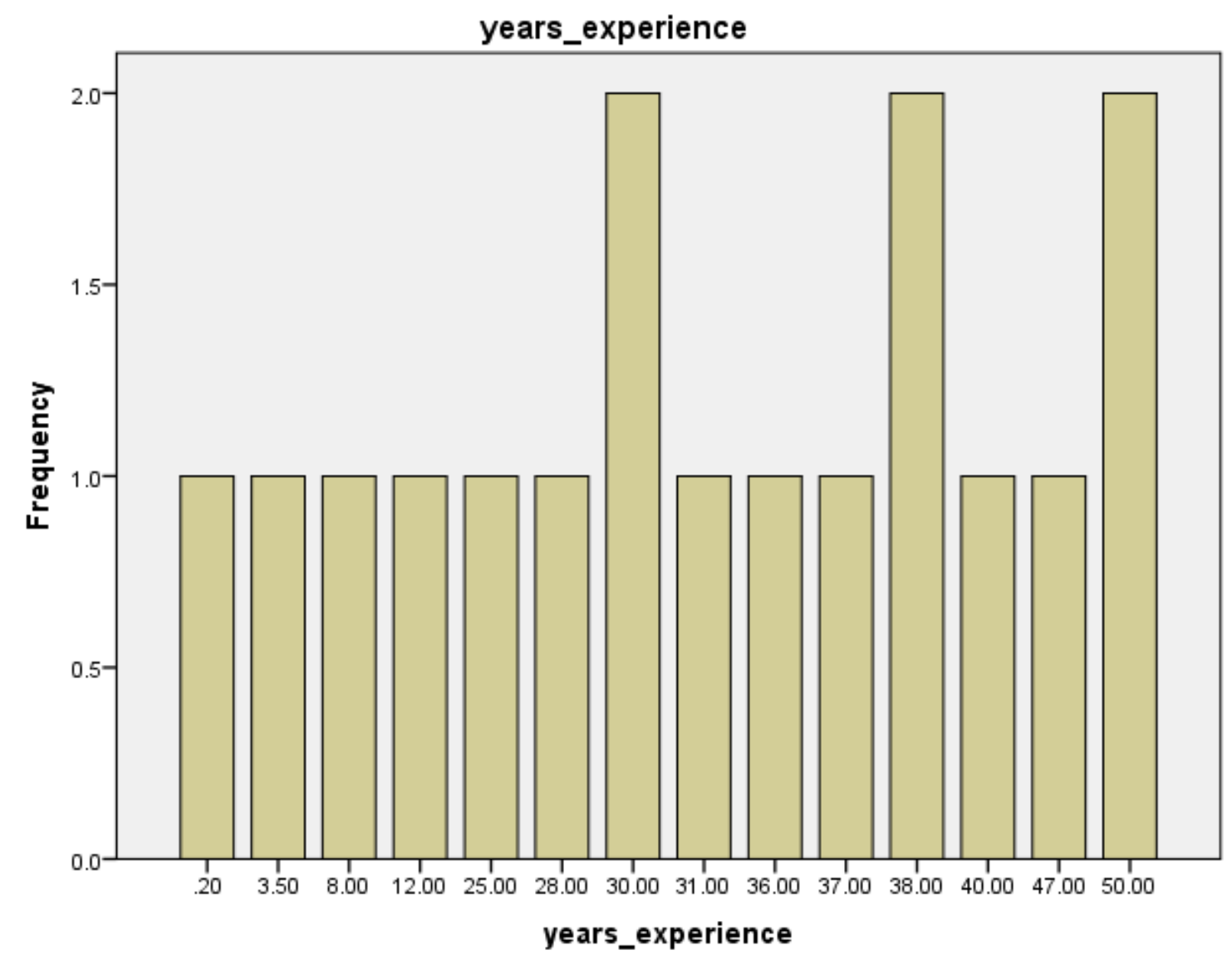

Figure 1. Years of RN experience 


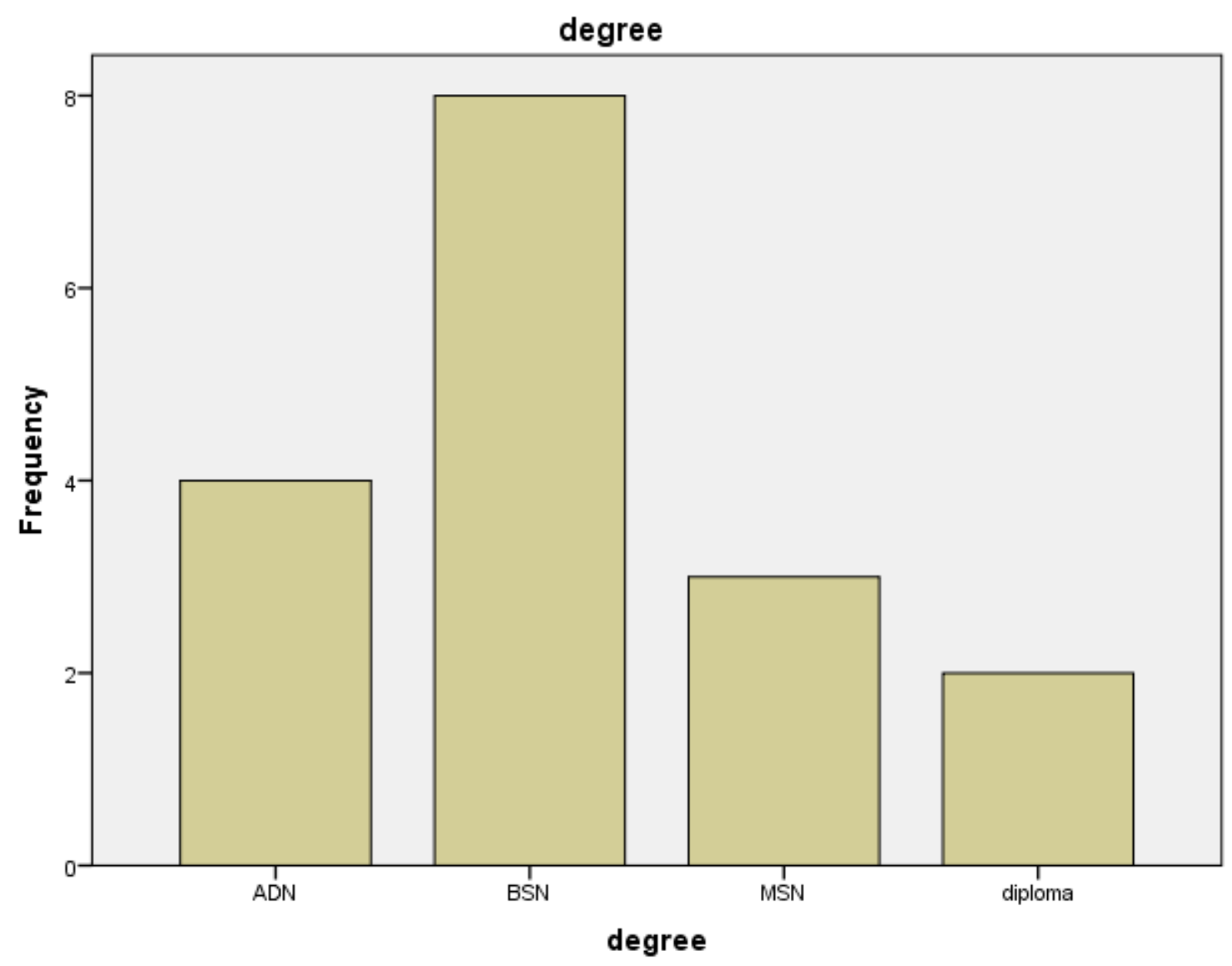

Figure 2. Highest degree in nursing

The participants in this doctoral research project were entirely female. They had varied ages, education, and nursing experience. The focus groups included both younger nurses and older nurses, but were skewed toward older nurses with decades of experience, especially in the second focus group. Focus group 1 had an average age falling between 30 and 39 years and an average years of registered nursing experience of 12.8 years with a standard deviation of 13.085 . The second and larger focus group's average age was between 50 and 59 years with an average years of registered nursing experience of 34.8 years with a standard deviation of 12.358. Participants were asked to identify all areas of nursing in which they have worked. The most common nursing experience for both groups 
was obstetrics. NICU and other non-specified were the next most common areas of nursing experience for focus group 1 and medical-surgical nursing and other non-specified areas for focus group 2. Perhaps not surprising given the average age of the participants, there were two participants who hold a diploma in nursing as their highest degree. The most common level of academic preparation was baccalaureate, with three masters-prepared registered nurses. Two participants did not indicate their highest degree in nursing.

\section{Breastfeeding Knowledge pre- and posttests}

A breastfeeding knowledge pre- and posttest was administered to all participants (see Table 2, 3, and 4). In order to use an existing test, the test was obtained from The Maternal and Child Health and Education Trust (2018). This test is available for use with the restriction that it not be changed. Due to this, there were two questions which are not applicable in the United States and were not addressed during the teaching portion of the focus groups: vitamin A administration and HIV positive mothers breastfeeding. To fulfill the requirement of using the test, these questions were included on the pre- and posttest. It was assumed that they would not affect change between pre- and posttest scores since participants who answered them correctly or incorrectly in the pretest would also answer them the same way in the posttest. In case that assumption turned out not to be true, statistics were run with and without the two nonapplicable questions.

Paired t-tests were run to compare the means of the pre- and posttest scores with all questions on the test and also without questions 7 and 9. Question 7 is about vitamin A and question 9 is about HIV and breastfeeding. Tables 2, 3, and 4 show the results. The first table includes all questions, followed by the results without the two irrelevant questions. 
Table 2

Breastfeeding Knowledge Paired Samples Combined Focus Groups Paired Samples Statistics using all questions

\begin{tabular}{lll|r|r|r} 
& & Mean & N & \multicolumn{1}{c|}{ Std. Deviation } & Std. Error Mean \\
\hline Pair 1 & Pretest total & 13.3684 & 19 & 1.64014 & .37627 \\
\cline { 2 - 6 } & Posttest total & 14.4737 & 19 & 2.65348 & .60875 \\
\hline
\end{tabular}

\section{Paired Samples Statistics without questions 7 and 9}

\begin{tabular}{rll|r|r|r} 
& & Mean & N & Std. Deviation & Std. Error Mean \\
\hline Pair 1 & preno7and9 & 11.8421 & 19 & 1.50049 & .34424 \\
\cline { 2 - 7 } & postno7and9 & 12.6316 & 19 & 2.69177 & .61753 \\
\hline
\end{tabular}

Table 3

Breastfeeding Knowledge Paired Samples t-test Combined Focused Groups Paired Samples Test using all questions

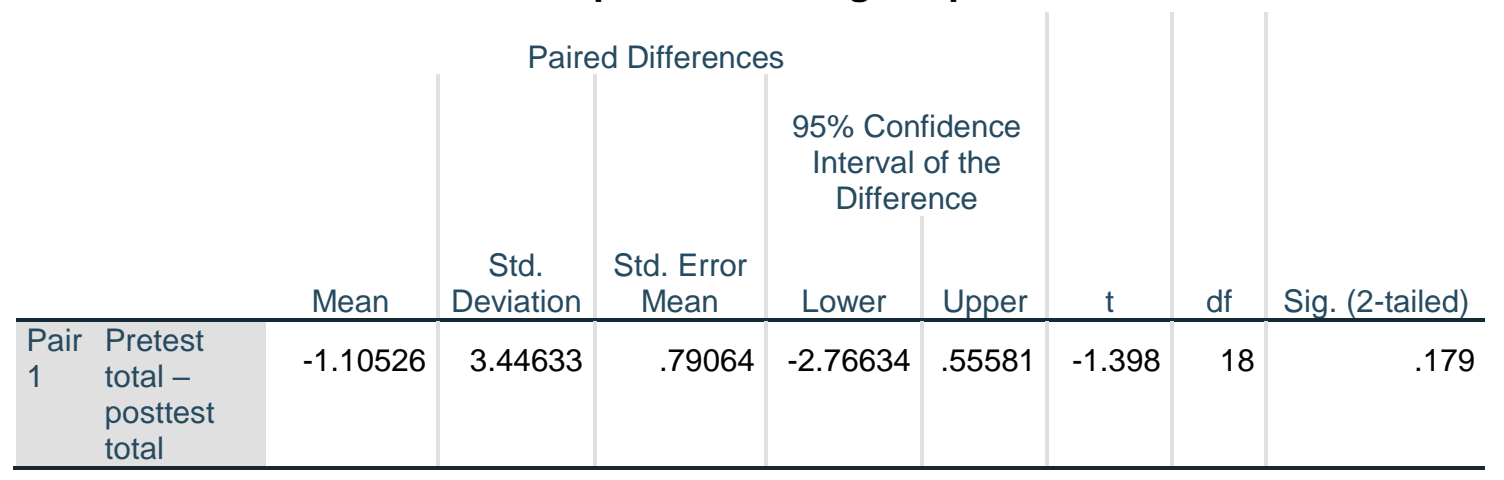

\section{Paired Samples Test without questions 7 and 9}

\begin{tabular}{|c|c|c|c|c|c|c|c|c|}
\hline \multicolumn{6}{|c|}{ Paired Differences } & \multirow[b]{3}{*}{$\mathrm{t}$} & \multirow[b]{3}{*}{ df } & \multirow[b]{3}{*}{ Sig. (2-tailed) } \\
\hline & & & & $\begin{array}{l}95 \% \text { Cont } \\
\text { Interval } \\
\text { Differe }\end{array}$ & $\begin{array}{l}\text { idence } \\
\text { of the } \\
\text { nce }\end{array}$ & & & \\
\hline & Mean & Deviation & Mean & Lower & Upper & & & \\
\hline $\begin{array}{ll}\text { Pair } 1 & \text { Partial } \\
\text { pre-partial } \\
\text { post }\end{array}$ & -.78947 & 3.42505 & .78576 & -2.44030 & .86135 & -1.005 & 18 & .328 \\
\hline
\end{tabular}


Table 4

Pre- and Posttest Correlations Combinded Focus Groups

Paired Samples Correlations using all questions

\begin{tabular}{lll|r|r} 
& & $\mathrm{N}$ & \multicolumn{1}{c}{ Correlation } & Sig. \\
\hline Pair 1 & $\begin{array}{l}\text { Pretest total \& } \\
\text { posttest total }\end{array}$ & 19 & -.247 & .309 \\
\hline
\end{tabular}

Paired Samples Correlations without questions 7 and 9

\begin{tabular}{lllll} 
& & N & \multicolumn{1}{c}{ Correlation } & Sig. \\
\hline Pair 1 & preno7and9 \& postno7and9 & 19 & -.277 & .252 \\
\hline
\end{tabular}

As shown in the pre/posttest statistics, there was no significant difference between the pretest scores and the posttest scores. Removing the non-applicable questions had minimal change on the results, which remained not significant. This is largely due to the high scores on the pretest. The pretest mean was 13.2684 out of 16 with two of the questions not applicable to our location and population. Without the two questions, results were 11.8421 out of 14 . When all questions were included, the mean posttest score increased by 1.1 to 14.4737 but the standard deviation also increased from 1.64 to 2.65 making the difference statistically insignificant and showing no meaningful correlation. When only the 14 applicable questions were included, the mean posttest score increased by 0.8 but again the standard deviation increased and the difference was not statistically significant.

There was also no significant difference between breastfeeding knowledge pre- and posttest scores when the focus groups are examined individually as shown in Table 5 and Table 6. 
Table 5

Paired Samples Using All Questions for Focus Group 1

\section{Paired Samples Test}

\begin{tabular}{|c|c|c|c|c|c|c|c|c|c|}
\hline & & & Pair & Differen & & & & & $\begin{array}{l}\text { Sig. (2- } \\
\text { tailed) }\end{array}$ \\
\hline & & & Std. & $\begin{array}{l}\text { Std. } \\
\text { Error }\end{array}$ & $\begin{array}{r}95 \% \text { Con } \\
\text { Interval } \\
\text { Differ }\end{array}$ & $\begin{array}{l}\text { dence } \\
\text { f the } \\
\text { ice }\end{array}$ & & & \\
\hline & & Mean & Deviation & Mean & Lower & Upper & $\mathrm{t}$ & $\mathrm{df}$ & \\
\hline Pair 1 & $\begin{array}{l}\text { Pretest } \\
\text { total - } \\
\text { posttest } \\
\text { total }\end{array}$ & -2.50000 & 1.73205 & .86603 & -5.25608 & .25608 & -2.887 & 3 & .063 \\
\hline
\end{tabular}

Table 6

Paired Samples Using All Questions for Focus Group 2

\begin{tabular}{|c|c|c|c|c|c|c|c|c|c|}
\hline & & & & d Sam & es Test & & & & \\
\hline & & & $\mathrm{Pai}$ & d Differen & & & & & \\
\hline & & & Std. & $\begin{array}{l}\text { Std. } \\
\text { Error }\end{array}$ & $\begin{array}{r}95 \% \text { Cor } \\
\text { Interva } \\
\text { Differ }\end{array}$ & $\begin{array}{l}\text { dence } \\
\text { ff the } \\
\text { nce }\end{array}$ & & & Sig. (2- \\
\hline & & Mean & Deviation & Mean & Lower & Upper & $\mathrm{t}$ & df & tailed) \\
\hline$\overline{P a i r} 1$ & $\begin{array}{l}\text { Pretest } \\
\text { total - } \\
\text { posttest } \\
\text { total }\end{array}$ & -.73333 & 3.73146 & .96346 & -2.79975 & 1.33308 & -.761 & 14 & .459 \\
\hline
\end{tabular}

Focus group 1 had a pretest mean score of 11.75 and posttest mean score of 14.2 with a standard deviation of 1.73 . This shows a significance level of 0.063 which does not meet the established significance level of 0.05. Focus group 2 had a pretest mean score of 13.8 and posttest mean score of 14.5 with a standard deviation of 3.73. The significance level was 0.226 which also does not meet the established level of significance.

When questions 7 and 9 are removed and statistics for the focus groups are run separately, the results still remain below the established level of significance. See Table 7 and Table 8. 
Table 7

Pre- and Posttest Correlations Focus Group 1 Without Questions 7 and 9

Sunday Focus Group Paired Samples Test Without Questions 7 and 9

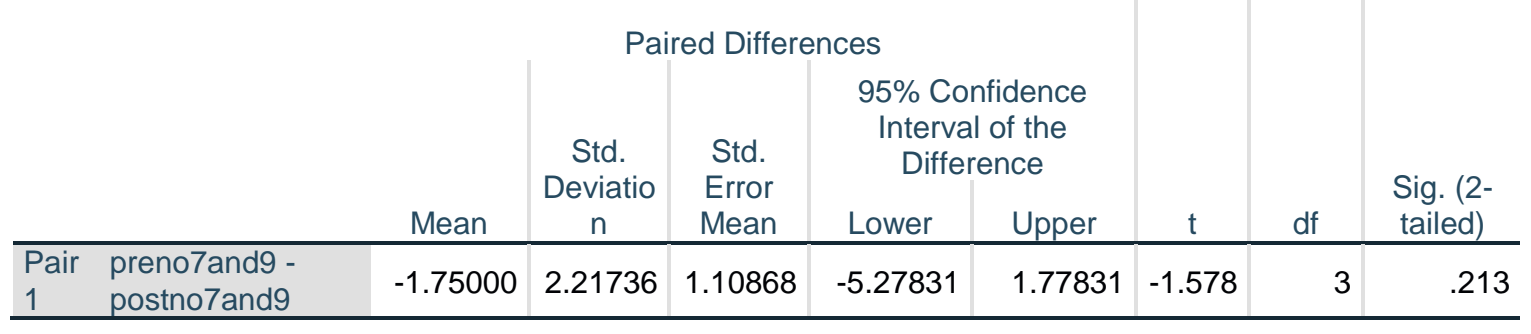

Table 8

Pre- and Posttest Correlations Focus Group 2 Without Questions 7 and 9

Monday Focus Group Paired Samples Test Without Questions 7 and 9

\begin{tabular}{|c|c|c|c|c|c|c|c|c|c|}
\hline & & \multicolumn{5}{|c|}{ Paired Differences } & \multirow[b]{3}{*}{$\mathrm{t}$} & \multirow[b]{3}{*}{ df } & \multirow{3}{*}{$\begin{array}{l}\text { Sig. (2- } \\
\text { tailed) }\end{array}$} \\
\hline & & \multirow[b]{2}{*}{ Mean } & \multirow{2}{*}{$\begin{array}{l}\text { Std. } \\
\text { Deviatio } \\
\text { n }\end{array}$} & \multirow{2}{*}{$\begin{array}{l}\text { Std. } \\
\text { Error } \\
\text { Mean }\end{array}$} & \multicolumn{2}{|c|}{$\begin{array}{l}95 \% \text { Confidence } \\
\text { Interval of the } \\
\text { Difference }\end{array}$} & & & \\
\hline & & & & & Lower & Upper & & & \\
\hline $\begin{array}{l}\text { Pair } \\
1\end{array}$ & $\begin{array}{l}\text { preno7and9- } \\
\text { postno7and9 }\end{array}$ & -.53333 & 3.70071 & .95552 & -2.58272 & 1.51605 & -.558 & 14 & .586 \\
\hline
\end{tabular}

The Sunday focus group pretest mean score was 1.7 lower than the posttest mean, but with a standard deviation of 2.2 the level of significance was 0.213 . The Monday focus group pretest mean only increased by 0.5 from 12.5 to 12.73 out of 14. This is not significant at 0.586 .

\section{Qualitative Data Results}

The primary focus of this doctoral project was to collect qualitative data from Registered Nurses on the Breastfeeding Support Training Program. After the 
guided discussions from the focus groups were transcribed, the data was evaluated utilizing NVivo to look for themes and word frequency.

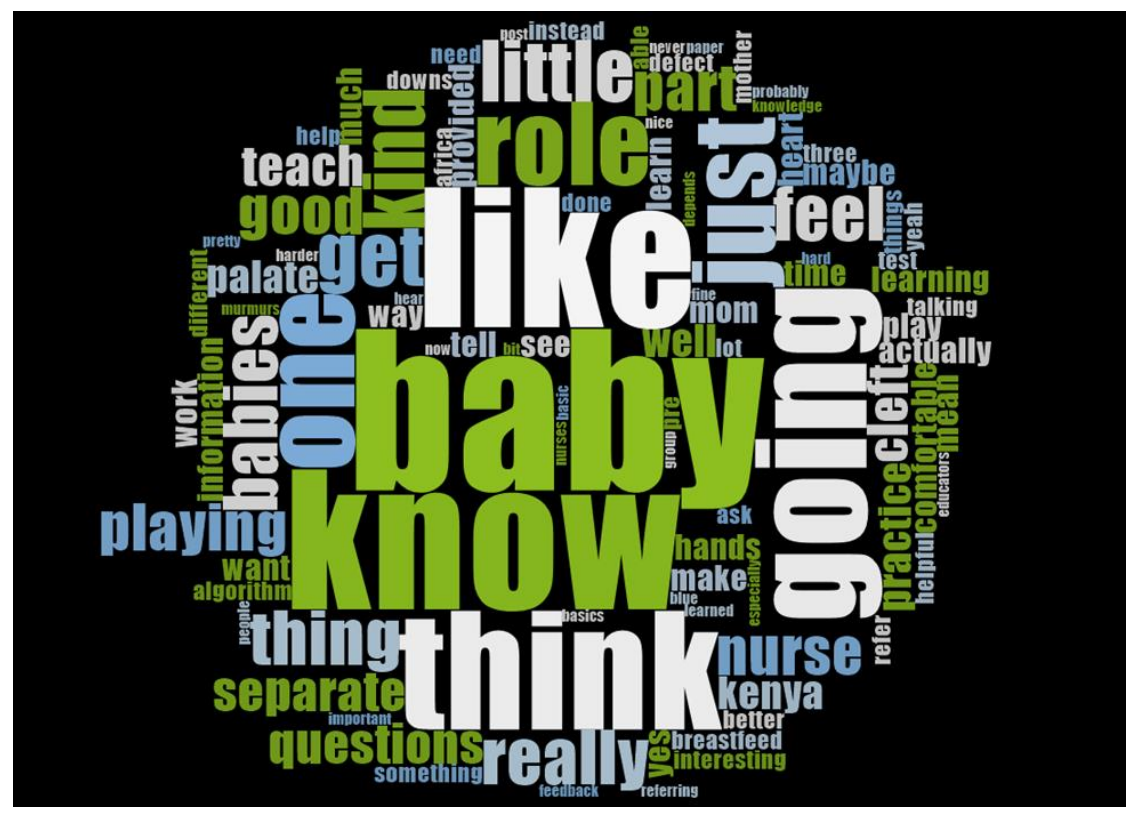

Figure 3. Word cloud of focus group discussion word frequency

The most frequent comments during the guided discussions were positive comments related to utilizing role play for teaching and assessing learning. Another common word in the discussion was baby which was often linked to doll or was addressing using a doll as the baby in role playing. Learners were very positive about utilizing a baby doll to promote kinesthetic, psychomotor learning.

The guided discussion transcripts were coded in NVivo. Applicable comments from participants were collated into nodes as pro, con, or neutral toward the breastfeeding training program. The transcripts along with the initial coding were distributed to the committee members. After some discussion and feedback from the committee, participant comments were condensed and coded into two categories: facilitators (portions of the program participants found helpful in learning breastfeeding support) and barriers (portions of the program participants found not helpful in learning breastfeeding support). Quotes from the focus group 
guided discussions which were identified as facilitators and barriers can be found in Appendix I. The themes identified as facilitators and barriers by the two focus groups are listed in Table 9.

\section{Table 9}

Focus Group Data Analysis-Identified Themes

\begin{tabular}{|c|c|c|}
\hline Question 1 & Facilitators & Barriers \\
\hline \multirow[t]{7}{*}{$\begin{array}{l}\text { Thoughts about } \\
\text { the } \\
\text { teaching/learning }\end{array}$} & Strong support for using dolls & $\begin{array}{l}\text { Anomalies algorithm } \\
\text { hard/confusing/too much } \\
\text { information }\end{array}$ \\
\hline & Strong support for role playing & Needed to refer to the algorithms \\
\hline & $\begin{array}{l}\text { Helpful having copies of } \\
\text { algorithms and OSCEs }\end{array}$ & \\
\hline & Participants learned a lot & \\
\hline & $\begin{array}{l}\text { Utilized multiple modes of } \\
\text { teaching }\end{array}$ & \\
\hline & Doing role plays as pair or trio & \\
\hline & Comfortable learning atmosphere & \\
\hline Question 2 & Facilitators & Barriers \\
\hline \multirow{5}{*}{$\begin{array}{l}\text { strengths or best } \\
\text { part of this } \\
\text { program }\end{array}$} & Using dolls & \\
\hline & Using role play & \\
\hline & Content and amount of learning & \\
\hline & $\begin{array}{l}\text { Switching roles between "mom" } \\
\text { and "nurse" }\end{array}$ & \\
\hline & Having the algorithms to reference & \\
\hline Question 3 & Facilitators & Barriers \\
\hline $\begin{array}{l}\text { weaknesses or } \\
\text { weakest part }\end{array}$ & $\begin{array}{l}\text { Comfortable, low-pressure } \\
\text { learning environment }\end{array}$ & $\begin{array}{l}\text { Too much/not clear on the algorithm } \\
\text { for anomalies }\end{array}$ \\
\hline
\end{tabular}




\begin{tabular}{|c|c|c|}
\hline & Well-prepared program & Poor print quality of algorithms \\
\hline & $\begin{array}{l}\text { Encourages keeping dialog open } \\
\text { with the mother }\end{array}$ & Vitamin A on pre/post test \\
\hline Question 4 & Facilitators & Barriers \\
\hline \multirow[t]{5}{*}{$\begin{array}{l}\text { Recommended } \\
\text { changes }\end{array}$} & $\begin{array}{l}\text { Hearing about differences } \\
\text { between the USA and Africa }\end{array}$ & Demonstrate latching \\
\hline & & $\begin{array}{l}\text { Edits need to be specific for } \\
\text { different countries where it is used }\end{array}$ \\
\hline & & $\begin{array}{l}\text { Should warn participants they will } \\
\text { be in each other's personal space }\end{array}$ \\
\hline & & $\begin{array}{l}\text { Separate the algorithm for the } \\
\text { different anomalies }\end{array}$ \\
\hline & & Include more on prematurity \\
\hline Question 5 & Facilitators & Barriers \\
\hline \multirow[t]{4}{*}{$\begin{array}{l}\text { How well } \\
\text { prepared to teach } \\
\text { breastfeeding? }\end{array}$} & $\begin{array}{l}\text { Comfort levels between } 7 \text { and } 10 \\
\text { out of } 10\end{array}$ & $\begin{array}{l}\text { Need to know beginning comfort } \\
\text { level and/or experience teaching } \\
\text { breastfeeding }\end{array}$ \\
\hline & Have a lot of good information & $\begin{array}{l}\text { Will not be able to answer every } \\
\text { Mother's questions }\end{array}$ \\
\hline & $\begin{array}{l}\text { Many participants had previous } \\
\text { breastfeeding teaching experience }\end{array}$ & \\
\hline & $\begin{array}{l}\text { Able to do it and reference the } \\
\text { algorithm as needed }\end{array}$ & \\
\hline Question 6 & Facilitators & Barriers \\
\hline \multirow{2}{*}{$\begin{array}{l}\text { How well } \\
\text { prepared to assist } \\
\text { with breastfeeding } \\
\text { an infant with an } \\
\text { anomaly or } \\
\text { defect? }\end{array}$} & We learned the basics & The algorithm was harder \\
\hline & $\begin{array}{l}\text { Teach that safety is most } \\
\text { important }\end{array}$ & Too much on the algorithm \\
\hline
\end{tabular}




\begin{tabular}{|l|l|l|}
\hline & $\begin{array}{l}\text { Able to try as long as there will be } \\
\text { follow up }\end{array}$ & Need more practice \\
\hline & & Need to learn more \\
\hline
\end{tabular}

\section{Facilitators}

The facilitators which emerged from the focus group transcripts validate the teaching style adopted for the Breastfeeding Support Training Program. The participants liked role playing in small groups using a doll. This created a low-

pressure learning environment they felt was highly conducive to learning. They felt trading roles increased learning and provided additional perspective. Also, they found the algorithms a good tool to ensure accurate and thorough teaching.

As the program is revised and moves forward toward additional data collection, this study indicates that the foundational teaching methods should not be changed. The Breastfeeding Support Training Program will continue to utilize role play for demonstration, practice, and return demonstration using OSCEs.

Additional facilitators which were identified were the ability to help a mother learn to breastfeed. Participants indicated that following the algorithms encourages open dialogue between the mother and nurse which should create a therapeutic relationship and identify the nurse as an available resource in case breastfeeding dysfunction arises later. The registered nurses participating in the focus groups did not feel as comfortable helping a mother breastfeed an infant with a common congenital anomaly or defect as they did a healthy infant. However, many stated they had enough information to help the mother begin as long as there was a referral source available should feeding or other medical problems arise.

\section{Barriers}

The barrier which was most often identified during the guided discussions was difficulty using the algorithm for common congenital defects and anomalies. 
There are several possible contributing factors for this. First, as the participants stated, there is a lot of information on the algorithm. Each anomaly requires different interventions. Finding and following the correct pathway of interventions may not have been as intuitive as was desired in creating the algorithm. Another probable contribution is the short time frame of the focus groups. Participants were asked to attend one 2-hour focus group. A longer focus group was thought to be an undue burden on participants and was expected to decrease the number of willing volunteers. Asking participants to return for a second focus group would have created problems with attrition. Two hours seemed like a reasonable amount of time to request from subjects, but mastering the algorithm for common anomalies and defects likely requires more time. As the Breastfeeding Support Training Program is revised and additional testing pursued, increasing the training session to either 4-hours or two 2-hour sessions should be considered.

Many participants commented that they would like more information and/or more practice before helping a mother attempt to breastfeed an infant with a common congenital anomaly or defect. Other subjects stated they would be comfortable at a beginning level. The discrepancy between these answers likely was affected by the Registered Nurse's prior experience with supporting breastfeeding and comfort with infants with medical needs.

This Breastfeeding Support Training Program is patterned after Helping Babies Survive. The creator of this program will use it to supplement Helping Babies Survive during training of nurses and birth attendants in Kenya, East Africa. Helping Babies Survive is meant to be implemented in resource-limited countries. This program was intended to cross cultures and socioeconomic barriers and be useful for infants with common congenital anomalies and defects in all settings. Registered nurses attending the second focus group felt the algorithms 
were not interchangeable between first world and developing world needs. They recommended tailoring the algorithms to the culture and location in which they will be utilized.

Only one participant commented on the poor print quality of the algorithms. The algorithms were created in Microsoft Word and sized for legal paper of $81 \frac{1}{2}$ by 14 inches. However, when the algorithms were printed on the larger paper, they became blurry. The print center who made the copies suggested the algorithms should be re-created in Publisher rather than Word. Before any further data is collected the algorithms will be edited and transferred to a program which will print at legal size without loss of clarity.

Additional barriers were identified related to the pre/posttest. A few of the focus group participants suggested either removing the two nonapplicable questions on the test or teaching about them. Due to the requirements associated with using the test, it was used without any changes even though two questions do not apply to the United States and were not addressed during the focus groups. It was felt those two questions would not have an impact on the test scores since the information would not be covered. If a participant happened to know the answers and got them right on the pretest, she should also get them right on the posttest; if a participant did not know the answers and got them wrong on the pretest, she should also get them wrong on the posttest. In order to better assess learning during the Breastfeeding Support Training Program, future studies should utilize a different pre/posttest or create a test which more closely aligns with the program.

\section{Analysis of the Data}

The two focus groups provided numerous helpful feedback data to the creator of the Breastfeeding Support Training Program. Additionally, the researcher wrote a memo after each focus group with observations and 
impressions. Data from these will be incorporated into the program revision. Based on the researcher's memos after the focus groups and responses during the guided discussion, some considerations and recommendations have been identified.

Explaining role playing. First, role playing needs to be explained. During the second focus groups, one table of participants with two older nurses and a younger nurse did not role play. They held the doll and talked, stating what they would say to the mother or what they would show the mother, but they did not actually perform what they were describing. It is likely the older nurses have never used simulation and role play for learning before. It is a newer teaching and learning modality. The younger nurse stated she is very comfortable teaching breastfeeding and teaches it routinely at her job. It is very possible the younger nurse was not motivated to help the older nurses learn how to role play, and the older nurses did not seem to understand they were not actually role playing.

Retain the sequence. This study showed the sequence of the Breastfeeding Support Training Program to be effective. The program should continue to begin with a short lecture to highlight the need and explain the goals of the program. Then, a role play demonstration will show how to utilize the algorithms. Next, participants will practice role playing with each other in small groups, trading roles between the "nurse" and the "breastfeeding mother." Finally, participants will check each other off using an OSCE.

Utilize OSCEs. Another conclusion from the focus groups is that utilizing OSCEs to assess learning seemed to be effective, but increasing the rigor of the check offs should be considered. During the focus groups, most participants used the OSCEs to guide rather than to test the learner. The OSCEs include designated prompts. However during the focus groups, the researcher noticed the participants 
were giving far more prompts than are listed on the OSCE. One possible solution will be to change the groups after practicing so the individuals checking each other off are not the same person or people with whom they did the role playing. This might decrease the urge to help the person they are assessing.

Revise the algorithm for infants with feeding dysfunction. It is clear from the focus group feedback that the algorithm for breastfeeding an infant with a common congenital anomaly or defect needs revision. Participants suggested separating the different medical conditions into individual algorithms. Typically, an algorithm is not a single line of actions for a single issue. Before separating the algorithm into multiple algorithms, it will be redesigned with a clearer path to follow based on yes-no responses. The first question for an infant who is not feeding well needs to be "is a murmur present? Yes or no?" An infant with another defect and a murmur should follow the interventions for an infant with a murmur. The next fork in the pathway will be "is the infant's appearance abnormal? Yes or no?" If no, then the pictures of trisomy 21 and cleft defects will be considered. If the infant resembles either of those pictures, the recommended related intentions will be listed. If an infant is not feeding well but does not show signs of a common congenital anomaly or defect there will be another path with recommended interventions.

Consider eliminating the second algorithm. Only algorithms 1 and 3 were taught during the focus groups due to time constraints. This poses the question of whether or not the second algorithm is really necessary. The first algorithm illustrates how to teach breastfeeding and address common complaints. The second algorithm guides the user through assessing for feeding dysfunction. If feeding dysfunction is present, the third algorithm identifies appropriate interventions for common congenital anomalies and defects. It may be possible to 
list the signs of feeding dysfunction at the bottom of the first algorithm and guide the user straight to the third algorithm. During actual training sessions, two algorithms instead of three would allow for additional time to be spent on the algorithm for common congenital anomalies and defects.

Consider changing or creating a pre/posttest for future research. Participants did not like having two questions on the pre/posttest which were not relevant to the training program. There are benefits to using an existing, broadlyused test, but only if the test matches the content which will be taught. It was assumed the irrelevant questions would not affect test scores since a participant who happened to know the answers would get it right on the pre- and posttest. A participant who did not know the answers would likely guess the same way each time, making the questions insignificant when comparing the total pre- and posttest scores. However, the guided discussion showed participants found the extraneous questions distracting and bothersome.

Ensure clear copies. Only one participant commented on the poor quality of the printing. However, the researcher was very unhappy about the poor resolution on the algorithms. In the future, the algorithms will be printed from a program other than Word. Different programs will be tried in order to find one which will print on legal-sized paper without losing clarity.

\section{Summary}

The breastfeeding support training program appears to be enjoyable for participants and to provide a good learning experience. Role play is effective and should be retained in the program. However, how to role play needs to be explained. Not all registered nurses understand how to role play. This was noticeable in the older nurses participating in the focus groups. Subjects in this 
study were on average older and the older nurses tended to have a lower academic degree in nursing, likely contributing to their lack of familiarity with role play.

Teaching by algorithm was a positive aspect of the program. Subjects found it helpful to refer to the algorithm to guide teaching, ensuring consistency and comprehensiveness. However, the algorithm for helping a mother breastfeed her infant with a common congenital anomaly or defect needs significant revisions.

The Breastfeeding Support Training Program in scheduled to be implemented in Kenya, East Africa in fall 2019. Additional study on the program and breastfeeding results will be collected. The current program was designed with the hope that it could be used in various settings and cultures. Study results from Kenya will determine if cultural variations need to be incorporated into the program. 


\section{CHAPTER 5: CONCLUSION}

Science, healthcare, and governmental agencies agree that infants, mothers, and society benefit from breastfeeding (American Academy of Pediatrics policy statement, 2018). Unfortunately, data shows most infants are not receiving breastmilk exclusively for six months as recommended (Centers for Disease Control and Prevention, 2014). One population at risk for no or minimal breastfeeding is infants of young, low education-level mothers. Another group with low breastfeeding rates is infants with congenital anomalies and defects. This doctoral project is designed to reach these two at-risk populations. Simple pictorial algorithms may help younger, less educated women to understand the breastfeeding teaching they receive. An algorithm was created specific to infants with common congenital anomalies and defects.

Intentional, focused interventions have been shown to improve breastfeeding rates. One way to increase breastfeeding rates is by increasing lactation consultant visibility and scheduled time with pregnant women during routine prenatal office visits (Bonuck, Stuebe, Barnett, Labbok, Fletcher, and Bernstein, 2014). Also, breastfeeding rates increased when breastfeeding support was increased and breastfeeding was treated as the "normal" way to feed an infant (Brockway, Benzies, and Hayden, 2017). Technology can be used to promote breastfeeding. WIC recipients who received regular text messages with links to breastfeeding support websites from a peer mentor breastfed longer (Harari et al., 2017). Additionally, meeting breastfeeding recommendations correlated with early skin-to-skin, breastmilk only in the hospital after birth, and caregiver support (Augustin, Donovan, Lozano, Massucci, and Wohlgemuth, 2014). 


\section{Study Conclusions}

This doctoral project sought to develop and test a new breastfeeding support training program. It succeeded in designing the program and receiving feedback from two focus groups of registered nurses. The nurses provided insights into the facilitators and barriers of the program.

This breastfeeding support training program utilizes simple algorithms to train perinatal registered nurses to teach, assess, and implement interventions as needed for breastfeeding mothers, including when the infant has a common congenital anomaly or defect. Teaching and assessing learning are done through role play and checked off using an OSCE. The teaching methods of this program were found to be enjoyable by the subjects. Participants also felt they learned a lot of valuable information. One concern identified by the researcher was that not all subjects understood how to role play. In future training sessions, role play will be described and explained. Subjects also felt the OSCEs were clear and helpful. Again, the researcher noted misuse of the OSCEs. Many participants used the OSCEs to guide the subjects being assessed rather than to verify learning. One possible way to counteract the subjects' impulse to help each other will be to have learners role play for learning in one small group, and then role play while being checked off in a different small group.

While subjects liked having and following an algorithm, they found the algorithm for infants with common anomalies and defects difficult to utilize. Currently, the final algorithm has three columns, each of which applies to a different anomaly or defect. The algorithm will be redesigned following a yes/no branching pattern in which each path is more clearly defined. The program contains three algorithms, however only the first and third were used in the focus groups. As the algorithms are revised, the pros and cons of two versus three 
algorithms will be considered. If three algorithms are retained, then the teaching sessions should be increased to at least four hours. This could be either two 2-hour sessions or one 4-hour session. If the training is to remain at two hours, then the algorithms need to be condensed to two. Three algorithms cannot be adequately taught in two hours.

\section{Recommendations for Future Study}

The focus groups which comprised this study identified the need to revise the breastfeeding support training algorithms. After revisions are completed, future studies will need to be conducted to ensure the new version of the algorithms is effective for training nurses to support breastfeeding including when the infant has a common congenital anomaly or defect. After the algorithms are shown to be valid and useful, additional study to assess efficacy of the program should be conducted. The overall goal of this program is to increase breastfeeding rates particularly for infants with common congenital anomalies and defects. A large-scale study should be conducted to compare breastfeeding duration and intensity of new mothers who received breastfeeding support from nurses trained with this breastfeeding support training program compared to new mothers who received breastfeeding support from perinatal nurses who did not receive the training.

Another area of recommended additional study is to compare implementation of the program in different countries and locations. This program is patterned after Helping Babies Survive and designed to be useful in lowresource communities and developing countries. Studies should be conducted to ensure the program is effective cross-culturally. Feedback from registered nurses in multiple countries and locations should be obtained and compared. Also, breastfeeding statistics on mother-infant dyads who receive teaching and support 
from nurses trained using the program should be compared to the general breastfeeding rates in those locations. This research project was designed to be a pilot study. Additional larger studies are needed to validate the program curriculum and assess for efficacy. 
REFERENCES 


\section{REFERENCES}

American Academy of Pediatrics. (2018a). AAP Policy statement: Breastfeeding and the use of human milk. [organization website]. Retrieved from https://www.aap.org/en-us/advocacy-and-policy/aap-healthinitiatives/Breastfeeding/Pages/AAP-Policy-on-Breastfeeding.aspx

American Academy of Pediatrics. (2018b). Helping Babies Survive. [organization website]. Retrieved from https://www.aap.org/en-us/advocacy-andpolicy/aap-health-initiatives/helping-babies-survive/Pages/default.aspx

American Cancer Society. (No date). What are the risk factors for childhood leukemia? [organization website]. Retrieved from https://www.cancer.org/cancer/leukemia-in-children/causes-risksprevention/risk-factors.html

Ansari, S., Abedi, P., Hasanpoor, S., \& Bani, S. (2014). The effect of interventional program on breastfeeding self-efficacy and duration of exclusive breastfeeding in pregnant women in Ahvaz, Iran. International Scholarly Research Notices. doi:10.1155/2014/510793

Augustin, A. L., Donovan, K., Lozano, E. A., Massucci, D. J., \& Wohlgemuth, F. (2014). Still nursing at 6 months: A survey of breastfeeding mothers. $M C N$ : The American Journal of Maternal/Child Nursing, 39(1), 50-55. doi:10.1097/01.NMC.0000437534.99514.dc

Awano, M., \& Shimada, K. (2010). Development and evaluation of a self care program on breastfeeding in Japan: A quasi-experimental study. International Breastfeeding Journal, 5(9). doi:10.1186/1746-4358-5-9 
Baby-Friendly USA. (2018). [Organization website]. Retrieved from https://www.babyfriendlyusa.org/

Barbas, K., \& Kelleher, D. (2004). Breastfeeding success among infants with congenital heart disease. Pediatric Nursing 30(4), 285-289.

Bartick, M., Reinhold, A. (2010). The burden of suboptimal breastfeeding in the United States: a pediatric cost analysis. Pediatrics, 125(5): e1048-e1056. doi: 10.1542/peds.2009-1616

Binns, C. (2016). The long-term public health benefits of breastfeeding. AsiaPacific Journal of Public Health, 28(1), 7-14.

Bonuck, K., Stuebe, A., Barnett, J., Labbok, M. H., Fletcher, J., \& Bernstein, P. S. (2014). Effect of primary care intervention on breastfeeding duration and intensity. American Journal of Public Health, 104(Supplement 1), S119S127. http://doi.org/10.2105/AJPH.2013.301360

Braungart, M. M., \& Braungart, R. G. (2018). In J. B. Butts \& K. L. Rich (Eds.), Philosophies and theories for advanced nursing practice (pp. 199-239).

Brockway, M., Benzies, K., \& Hayden, K. A. (2017). Interventions to improve breastfeeding self-efficacy and resultant breastfeeding rates: A systematic review and meta-analysis. Journal of Human Lactation, 33(3), 486-499. doi:10.1177/0890334417707957

Burianova, I., Kulihova, K., Vitkova, V., \& Janota, J. (2017). Breastfeeding after early repair of cleft lip in newborns with cleft lip or cleft lip and palate in a 
baby-friendly designated hospital. Journal of Human Lactation, 33(3), 504508. doi:10.1177/0890334417706062

Centers for Disease Control and Prevention. (2014). Breastfeeding report card: United States/2014. Retrieved from https://www.cdc.gov/breastfeeding/data/reportcard.htm

Centers for Disease Control and Prevention, National Center on Birth Defects and Developmental Disabilities. (2017). Facts about cleft lip and palate. [Public domain images]. Retrieved from https://www.cdc.gov/ncbddd/birthdefects/cleftlip.html

Colón, E., Dávila-Torres, R. R., Parrilla-Rodríguez, A. M., Toledo, A., GorrínPeralta, J. J., \& Reyes-Ortiz, V. E. (2009). Exploratory study: Barriers for initiation and/or discontinuation of breastfeeding in mothers of children with down syndrome. Puerto Rico Health Sciences Journal, 28(4), 340-344.

Gaba, D. M. (2007). Simulation in healthcare. The Journal of the Society for Simulation in Healthcare, 2(2), 126-135. doi:10.1097/01.SIH.0000258411.38212.32

Graneheim, U. H., \& Lundman, B. (2004). Qualitative content analysis in nursing research: concepts, procedures and measures to achieve trustworthiness. Nurse Education Today, 24(2), 105-112. doi:10.1016/j.nedt.2003.10.001. PMID 14769454. 
Harari, N., Rosenthal, M. S., Bozzi, V., Goeschel, L., Javewickreme, T., Onvebeke, C., Griswold, M., \& Perez-Escamilla R. (2017). Feasibility and acceptability of a text message intervention used as an adjunct tool by WIC breastfeeding peer counsellors: The LATCH pilot. Maternal and Child Nutrition, DOI 10.1111/mcn.12488

Hays, D. G., \& Singh, A. A. (2011). Qualitative inquiry in clinical and educational settings. New York, NY: Guilford press.

Hsieh, H.-F., \& Shannon, S. E. (2005). Three Approaches to Qualitative Content Analysis. Qualitative Health Research, 15(9), 1277-1288. https://doi.org/10.1177/1049732305276687

Johnston, S., Coyer, F. M., \& Nash, R. (2018). Kirkpatrick's Evaluation of Simulation and Debriefing in Health Care Education: A Systematic Review. Journal of Nursing Education, 57(7), 393-398. https://doiorg.hmlproxy.lib.csufresno.edu/10.3928/01484834-20180618-03

Lavoie, P and Clarke, S. P. (2017). Simulation in nursing education. Nursing 2019, 47 (7), 18-20. doi: 10.1097/01.NURSE.0000520520.99696.9a

Lucina foundation. (no date). Image of signs of trisomy 21 in an infant. [image]. Used with permission. Retrieved from https://www.pinterest.com/pin/341288477988973735/?lp=true

Magenis, M. L., Machado, A. G., Bongiolo, A. M., Silva, M. d., Castro, K., \& Perry, I. S. (2018). Dietary practices of children and adolescents with Down syndrome. Journal of Intellectual Disabilities, 22(2), 125-134. doi: $10.1177 / 1744629516686571$ 
March of Dimes. (2018). Breastfeeding is best. [organization website]. Retrieved from https://www.marchofdimes.org/baby/breastfeeding-is-best.aspx

Martino, K., Wagner, M., Froh, E. B., Hanon, A. L., \& Spatz, D. L. (2015). Postdischarge breastfeeding outcomes of infants with complex anomalies that require surgery. Journal of Obstetric, Gynecologic \& Neonatal Nursing, 44 (3), 450-457. doi: 10.1111/1552-6909.12568

The Maternal and Child Health and Education Trust. (2018). Mother and child nutrition: Mother, infant and young child nutrition and malnutrition. [website]. http://motherchildnutrition.org/index.html

McLeod, S. (2016). Bandura-Social Learning Theory. Simply Psychology. Retrieved from https://www.simplypsychology.org/bandura.html

Mduma E., Ersdal H., Svensen E., Kidanto H., Auestad B., \& Perlman, J. (2018). Frequent brief on-site simulation training and reduction in $24-\mathrm{h}$ neonatal mortality--an educational intervention study. Journal of Resuscitation, 93:1-7. doi: 10.1016

Odom, E. C., Li, R., Scanlon, K. S., Perrine, C. G., \& Grummer-Strawn, L. (2013). Reasons for earlier than desired cessation of breastfeeding. Pediatrics. doi:10.1542/peds.2012-1295

Resnick, B. (2008). Theory of self-efficacy. In M. J. P. R. N. Smith \& P. R. P. A. Liehr (Eds.), Middle range theory for nursing. New York: Springer Publishing Company. 
Rosen, K. R. (2008). The history of medical simulation. Journal of Critical Care, 23(2), 157-166. doi: 10.1016j.jcrc.2007.12.004

Sooben, R. D. (2012). Breastfeeding patterns in infants with down's syndrome: A literature review. British Journal of Midwifery, 20(3), 187-192.

Spatz, D. L. (2011). Case studies in breastfeeding success for infants with congenital surgical anomalies. Journal of Obstetric, Gynecologic and Neonatal Nursing, Supplement 1(40), S133-134.

http://dx.doi.org.hmlproxy.lib.csufresno.edu/10.1111/j.15526909.2011.01244_19.x

Stuebe, Horton, Chetwynd, Watkins, Grewen, \& Metzer-Brody. (2014). Prevalence and risk factors for early, undesired weaning attributed to lactation dysfunction. Journal of Women's Health. 23(5):404-12. doi: 10.1089/jwh.2013.4506

Sutton, R. M., Niles, D., Meaney, P. A., Aplenc, R., French, B., Abella, B. S., Lengetti, E. L., Berg, R. A., Helfaer, M. A., \& Nadkarni, V. (2011). Lowdose, high-frequency CPR training improves skill retention of in-hospital pediatric providers. Pediatrics, 128(1).

US Department of Health and Human Services, Office of Disease Prevention and Health Promotion (2018). Healthy People 2020 [website]. Retrieved from: https://www.healthypeople.gov/2020/Leading-Health-Indicators

US Department of Health and Human Services, Office on Women's Health (2018). Breastfeeding [website]. Retrieved from https://www.womenshealth.gov/breastfeeding/ 
Willcox, M., Harrison, H., Asiedu, A., Nelson, A., Gomez, P., \& LeFevre, A. (2017). Incremental cost and cost-effectiveness of low-dose, high-frequency training in basic emergency obstetric and newborn care as compared to status quo: part of a cluster-randomized training intervention evaluation in Ghana. Globalization \& Health, 13, 1-14. https://doiorg.hmlproxy.lib.csufresno.edu/10.1186/s12992-017-0313-x

Worrall, K. (2007). A critical analysis of breastfeeding in a paediatric cardiac intensive care unit. Journal of Neonatal Nursing, 13(2), 51-57.

World Health Organization. (2018). [Organization website]. Baby-friendly hospital initiative. Retrieved from https://www.who.int/nutrition/bfhi/en/

World Health Organization. (2018). [Organization website]. Exclusive breastfeeding. Retrieved from http://www.who.int/nutrition/topics/exclusive_breastfeeding/en/ 
APPENDICES 


\section{APPENDIX A: BREASTFEEDING TEACHING ALGORITHMS}




\section{Basic Breastfeeding Teaching}

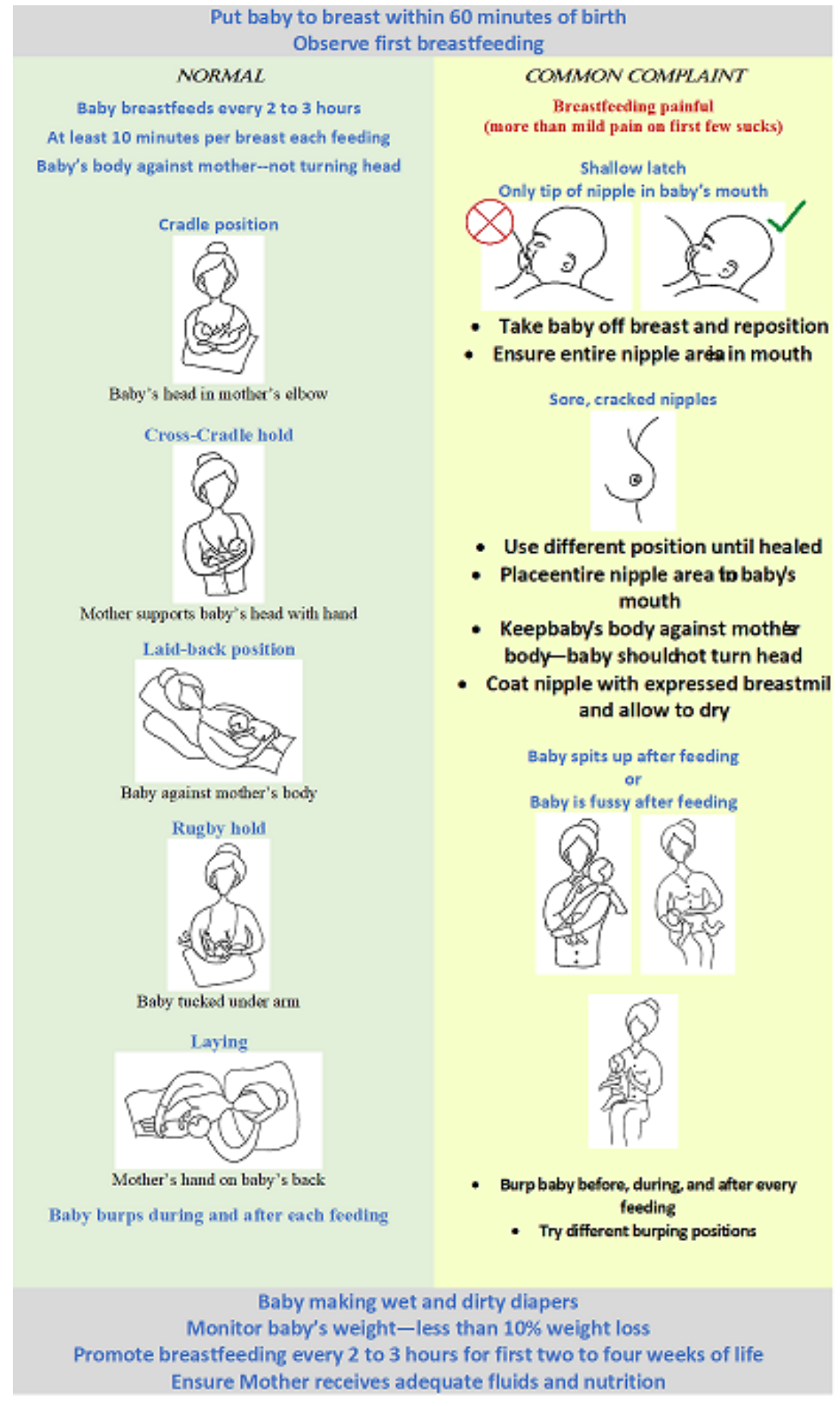


BREASTFEFDING FIOW CIIART-ASSFSSING FOR PROBIFMS

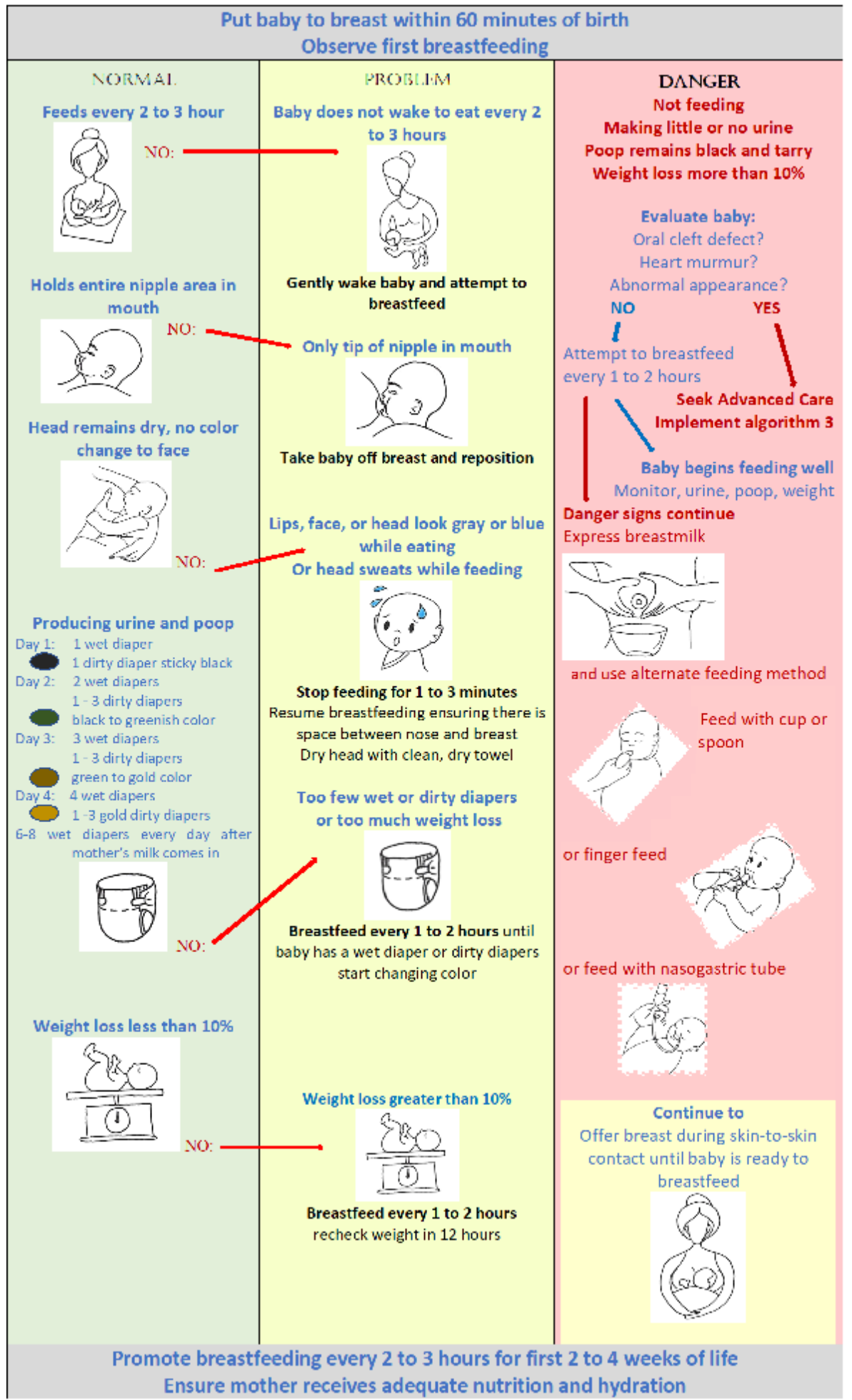




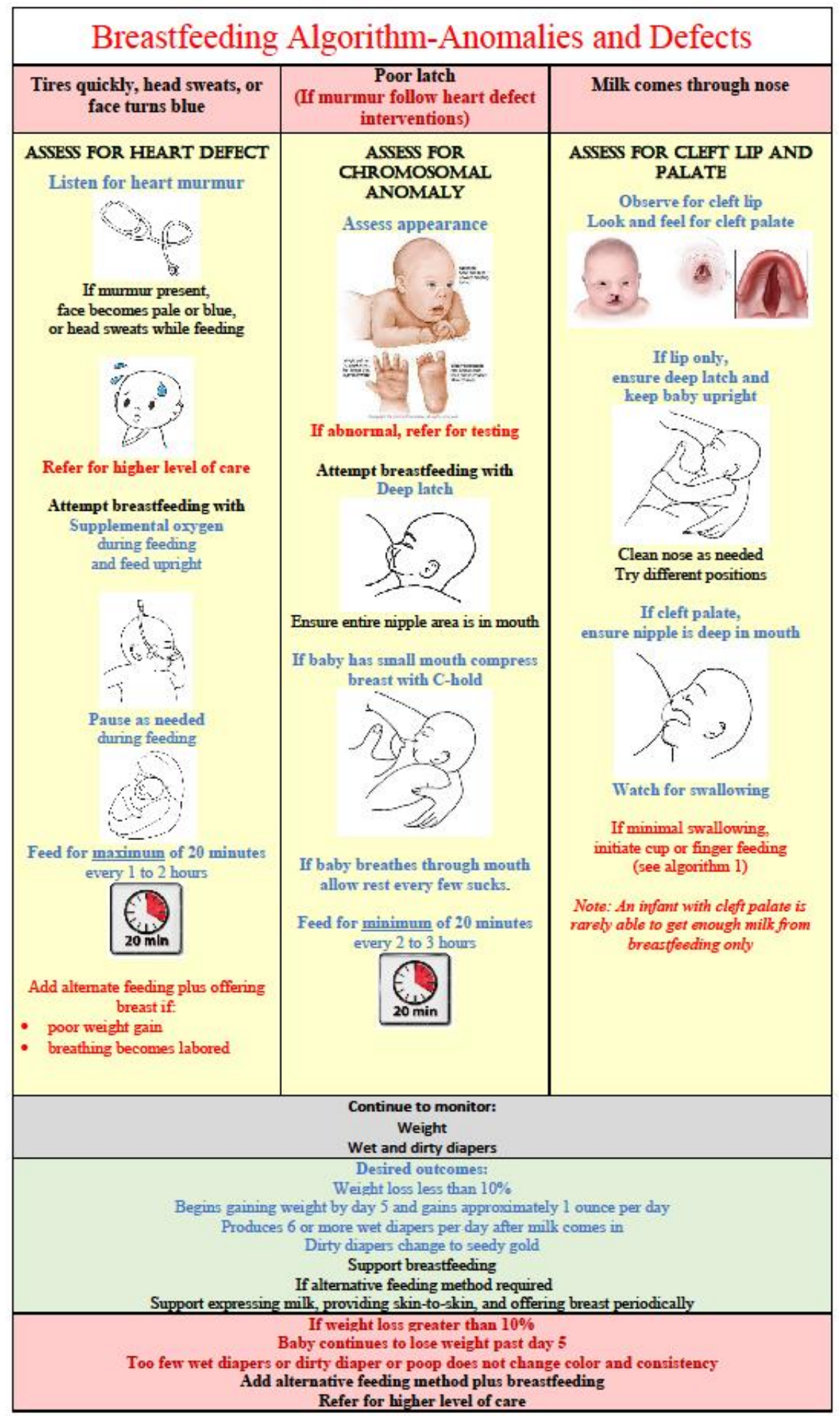


APPENDIX B: DEMOGRAPHIC FORM 


\section{Participant Demographic Data}

Randomized ID number:

Please fill out the following questions. If you are not sure of a specific answer, give the closest estimate you can.

Your current age (mark one):
$\square$ Under 30 years of age
$\square 30-39$
$\square 40-49$
$\square 50-59$
$\square 60$ or more

Gender:

Years as an $\mathrm{RN}$ :

Area/s of experience in nursing (mark all that apply):

$\square$ obstetrics (prenatal, labor and deliver, and/or postpartum)

$\square$ newborn nursery or NICU

$\square$ pediatrics

$\square$ medical surgical

$\square$ other (list areas)

Highest degree in nursing: 
APPENDIX C: BREASTFEEDING KNOWLEDGE TEST 
Mother and Child Nutrition

Mother, Infant, young child nutrition and malnutrition

Knowledge Tests - Breastfeeding

This interactive knowledge test is currently under development.

\begin{tabular}{|c|c|c|c|}
\hline$\#$ & Questions: & Yes & No \\
\hline & It is good to put the baby on the breast within one hour after birth. & & \\
\hline & $\begin{array}{l}\text { In order to have enough milk a mother needs to breastfeed every } 4 \text { hours (at least six } \\
\text { times a day). }\end{array}$ & & \\
\hline & Colostrum or First Milk serves as the first immunization for the baby. & & \\
\hline & $\begin{array}{l}\text { In the first six months, the infant needs water and/or other drinks in addition to breast } \\
\text { milk. }\end{array}$ & & \\
\hline & When breastfeeding, the baby's chin needs to touch the mother's breast. & & \\
\hline 6. & A malnourished infant and young child has more episodes of diarrhea. & & \\
\hline 7. & Vitamin A supplementation is necessary only for children under 2 years. & & \\
\hline 8. & Breastfeeding benefits the baby, but not the mother. & & \\
\hline & $\begin{array}{l}\text { When a mother is HIV-positive, there are ways to decrease HIV transmission to the } \\
\text { baby. }\end{array}$ & & \\
\hline & $\begin{array}{l}\text { Even if a mother believes she does not have enough breast milk, she can still be able to } \\
\text { adequately breastfeed her baby. }\end{array}$ & & \\
\hline & $\begin{array}{l}\text { A mother can prevent sore and cracked nipples by correctly positioning and attaching } \\
\text { her baby at the breast. }\end{array}$ & & \\
\hline & $\begin{array}{l}\text { The most important thing a mother can do to produce sufficient breast milk is to } \\
\text { breastfeed her baby frequently, both day and night. }\end{array}$ & & \\
\hline & $\begin{array}{l}\text { Infant formula contains antibodies that protect against diseases, especially against } \\
\text { diarrhea, respiratory and ear infections. }\end{array}$ & & \\
\hline & $\begin{array}{l}\text { Mixed feeding (meaning breastfeeding and giving other foods and drinks) before six } \\
\text { months can cause diarrhea, respiratory and ear infections. }\end{array}$ & & \\
\hline & A pregnant woman can continue breastfeeding. & & \\
\hline & Expressed breast milk can be stored in room temperature up to 1 day. & & \\
\hline
\end{tabular}


Mother and Child Nutrition

Key for

Mother, Infant, young child nutrition and malnutrition

Knowledge Tests - Breastfeeding

This interactive knowledge test is currently under development.

\begin{tabular}{|c|c|c|c|}
\hline \# & Questions: & Yes & No \\
\hline & It is good to put the baby on the breast within one hour after birth. & $\mathrm{X}$ & \\
\hline & $\begin{array}{l}\text { In order to have enough milk a mother needs to breastfeed every } 4 \text { hours (at least six } \\
\text { times a day). }\end{array}$ & & $\mathrm{X}$ \\
\hline & Colostrum or First Milk serves as the first immunization for the baby. & $\mathrm{X}$ & \\
\hline & $\begin{array}{l}\text { In the first six months, the infant needs water and/or other drinks in addition to breast } \\
\text { milk. }\end{array}$ & & $\mathrm{X}$ \\
\hline & When breastfeeding, the baby's chin needs to touch the mother's breast. & $\mathrm{X}$ & \\
\hline & A malnourished infant and young child has more episodes of diarrhea. & $\mathrm{X}$ & \\
\hline & Vitamin A supplementation is necessary only for children under 2 years. & & $\mathrm{X}$ \\
\hline & Breastfeeding benefits the baby, but not the mother. & & $\mathrm{X}$ \\
\hline & $\begin{array}{l}\text { When a mother is HIV-positive, there are ways to decrease HIV transmission to the } \\
\text { baby. }\end{array}$ & $\mathrm{X}$ & \\
\hline & $\begin{array}{l}\text { Even if a mother believes she does not have enough breast milk, she can still be able to } \\
\text { adequately breastfeed her baby. }\end{array}$ & $\mathrm{X}$ & \\
\hline & $\begin{array}{l}\text { A mother can prevent sore and cracked nipples by correctly positioning and attaching } \\
\text { her baby at the breast. }\end{array}$ & $\mathrm{X}$ & \\
\hline & $\begin{array}{l}\text { The most important thing a mother can do to produce sufficient breast milk is to } \\
\text { breastfeed her baby frequently, both day and night. }\end{array}$ & $\mathrm{X}$ & \\
\hline & $\begin{array}{l}\text { Infant formula contains antibodies that protect against diseases, especially against } \\
\text { diarrhea, respiratory and ear infections. }\end{array}$ & & $\mathrm{X}$ \\
\hline & $\begin{array}{l}\text { Mixed feeding (meaning breastfeeding and giving other foods and drinks) before six } \\
\text { months can cause diarrhea, respiratory and ear infections. }\end{array}$ & $\mathrm{X}$ & \\
\hline & A pregnant woman can continue breastfeeding. & $\mathrm{X}$ & \\
\hline & Expressed breast milk can be stored in room temperature up to 1 day. & & $\mathrm{X}$ \\
\hline
\end{tabular}

License: creative commons, use with attribution and without changes. Retrieved from http://motherchildnutrition.org/healthy-nutrition/about-essential-nutrition-actions/knowledgetests-breastfeeding.html\#.Wr_Bt1loL8I.email 
APPENDIX D: OBJECTIVE STRUCTURED CLINICAL SKILLS EXAM (OSCEs) 


\section{Breastfeeding algorithms \\ OSCE A \\ Instructions to facilitator}

Read aloud to the learner the following instructions and the case. Provide prompts where shown in italics (following the word "Prompt") if needed. As you observe the learner, tick the boxes Done or Not Done.

"I am going to read a role play case. Please listen carefully, and then show me or tell me what you would do to take care of this baby. I will answer any questions about the baby's condition. I will not volunteer information unless you ask. I will provide no other feedback until the end of the case."

"A 22-year-old mother has given birth to her first baby. The placenta has been delivered. Mother and baby are doing well. The baby cried at birth and is now 15 minutes old and wide awake. The mother wants to breastfeed but is unsure what to do. Show me what you would do to help this mother and baby breastfeed. Teach the mother multiple positions to breastfeed. Tell her about common problems and ways to treat them. State the assessments you would make to ensure the baby is getting enough milk."

Done Not Done

Washes hands.

Recommends feeding every 2-3 hours

Recommends feeding at least 10 minutes each feed...

\section{Assists with proper positioning of mother and baby}

Describes good attachment.......Prompt "What does good attachment look like? "..........

Demonstrates cradle hold.

Demonstrates cross cradle hold.

Demonstrates rugby hold.

Demonstrates laid back hold

Demonstrates lying.

Management of problems Prompt for each "Mother is having problems with..."

Pain while feeding.....take off and reposition

Cracked nipple.......coat with milk and allow to dry

Baby spiting up or fussy.... Burping. Teach 3 positions

Assess for adequate intake Prompt "How do you know baby is getting enough?"

Wet diapers ( 1 day $1 ; 2$ day 2; 3 day 3; 5-6 after milk comes in)...

Stools change color (black day 1; some green day 2; some gold day 3)

Listen for swallowing.

Weight loss less than $10 \%$ of birth weight.

SCORING: Successful completion requires a total score of 13 correct of 16 "Done". Incompletely done items should be marked as "Not done". 
Breastfeeding Algorithms

OSCE B

\section{Instructions to facilitator}

Read aloud to the learner the following instructions and the case. Provide prompts where shown in italics (following the word "Prompt") if needed. As you observe the learner, tick the boxes Done or Not Done.

"I am going to read a role play case. Please listen carefully, and then show me or tell me what you would do to assist this mother and baby with breastfeeding. I will answer any questions about the baby's condition. I will not volunteer information unless you ask. I will provide no other feedback until the end of the case".

"A mother returns to the center with her 5-day-old infant. The baby was born at $3.5 \mathrm{~kg}$ (7lbs $11 \mathrm{oz})$ and discharged home at 24 hours of life. The mother has been breastfeeding exclusively but is concerned the baby is not receiving enough milk. Describe the assessments you will do and your recommendations."

Done Not Done

Washes hands.

Assesses breastfeeding Prompt "How do you know if baby is breastfeeding well?"

Asks if baby is feeding every 2-3 hours.

Asks how long baby feeds at each feeding.

Asks/listens for swallowing....

Asks if baby has been weighted. States $10 \%$ loss as needing intervention

Asks if breasts soften after feeding.....

Asks number of wet diapers per day

Asks color, constancy of dirty diapers

Asks or assesses latch.

\section{Assess for cardiac problem}

Assesses for murmur.

Asks or assesses for sweating on head

Asks or assesses for pallor or cyanosis.

\section{Assess for trisomy 21}

Asks or assess for trisomy 21 appearance (eyes, ears, mouth, tone, hands, feet). Lists at least 3 signs......

Assess for oral cleft defect Prompt "Something is wrong with the baby's mouth"

Asks or assesses for milk coming out nose.

Assesses roof of mouth for cleft.

Recommendations for a problem Prompt "what should you do if you find a problem?"

Refer to physician/higher level of care

Feed upright.

Pause as needed during feeds to "catch breath"

Ensure deep latch.

Feed no more than 20 minutes every 1-2 hours if murmur present (must also refer).......

Feed minimum of 20 minutes every 2-3 hours if weak suck.

SCORING: Successful completion requires a total score of 16 correct of 20 "Done". Incompletely done items should be marked as not done. 
APPENDIX E: GUIDED DISCUSSION QUESTIONS 


\section{Guided Discussion Plan}

Leader to read:

"Please answer and discuss the following questions honestly. There are no right answers. People may have differing opinions, and everyone's opinion-including constructive criticism - is wanted and helpful for improving the algorithms. This discussion will be audio taped. The audio tape will only be heard by me and I will destroy it as soon as it is transcribed. The transcription will not identify the individual who made the comment."

1. What are your thoughts about the teaching/learning you just completed?

2. What do you think are the strengths of this program? Or what do you think was the best part of this program?

3. What do you think are weaknesses of this program? Or what do you think was the weakest part of this program?

4. What changes to the program would you recommend?

5. How well prepared do you feel to teach a client how to breastfeed?

6. How well prepared do you feel to help a client with an infant with a congenital defect or anomaly to attempt breastfeeding? 
APPENDIX F: CONSENT FORM 
BREASTFEEDING TEACHING ALGORITHM STUDY

You are invited to participate in a study conducted by Dr. Carrie Holschuh and Gretchen Ezaki through the California State University Northern California Consortium Doctor of Nursing Practice. We hope to gain nurses opinions on the strengths, weaknesses, and usefulness of simple, pictorial breastfeeding teaching algorithms for teaching breastfeeding and assessing and supporting breastfeeding for infants with congenital anomalies and defects. You were selected as a possible participant in this study because you are a perinatal Registered Nurse.

If you decide to participate, you will attend one 2-hour long focus group, during which you will complete a breastfeeding knowledge pre- and post-test, demographic questionnaire, receive training utilizing breastfeeding algorithms, return demonstrate applying the algorithms, and participate in a group guided discussion of the strengths, weaknesses, and usefulness of the algorithms. We will audio record the guided discussion for purposes of analysis. The audio recording will be transcribed word-for-word without identifying the speaker, and the original recording will be permanently deleted. It will never be uploaded to a cloud-based storage or placed on a computer where deleted files can be retrieved. The breastfeeding knowledge tests and demographic data will be labeled with a random number to ensure anonymity. The breastfeeding pre- and post-test will be statistically compared to assess learning, and the demographic data will be analyzed to describe the focus groups. Inconveniences of participating include loss of the time, and the possibility of discomfort or emotional stress from participating in a focus group and group guided discussion. Potential benefits include increased knowledge of supporting breastfeeding for you and the healthcare community. We cannot guarantee, however, that you will receive any benefits from this study.

Results of this study will be presented at the California State University Northern California Doctor of Nursing Practice oral defense presentations in May 2019. Also, the algorithms and study will be submitted to various healthcare journals for publication. Subjects will remain anonymous. Dissemination is to increases breastfeeding knowledge of perinatal nurses and improve breastfeeding rates, particularly for infants with congenital anomalies and defects.

If you choose to participate, you will receive no monetary compensation. There will also be no cost for participating other than your time. Risks of participation are limited to stress or discomfort from participating in a focus group with teaching, testing, and guided discussion.

Your decision whether or not to participate will not prejudice your future relations with California State University, Fresno or Pregnancy Care Center, Fresno. If you decide to participate, you are free to withdraw your consent and to discontinue participation at any time without penalty. The Committee for the Protection of Human Subjects at California State University, Fresno has reviewed and approved the present research.

If you have any questions, please ask us. You may contact Gretchen Ezaki at 559-978-1684 or Kelli Klassen at

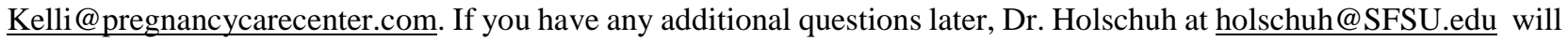
be happy to answer them. Questions regarding the rights of research subjects may be directed to Dr. Kris Clarke, Chair, CSU Fresno Committee on the Protection of Human Subjects, (559) 278-2985.

You will be given a copy of this form to keep.

YOU ARE MAKING A DECISION WHETHER OR NOT TO PARTICIPATE. YOUR SIGNATURE INDICATES THAT YOU HAVE DECIDED TO PARTICIPATE, HAVING READ THE INFORMATION PROVIDED ABOVE. Date Signature

Signature of Witness (if any)
Signature of Investigator 
APPENDIX G: IRB ACCEPTANCE 


\title{
FRESN@STATE \\ College of Health and Human Services
}

\author{
California State University, Fresno \\ School of Nursing \\ IRB Approval
}

Date: August 27, 2018

RE: DNP 1803 Study of Breastfeeding Training Program Designed Particularly for Infants with Congenital Anomalies and Defects

Dear Gretchen Ezaki,

As the Chair of the School of Nursing Research Committee, serving as the Institutional Review Board for the School of Nursing, I have reviewed and approved your review request for the above-referenced project for a period of 12 months. I have determined your study to meet the criteria for Minimal Risk IRB review.

Under the Policy and Procedures for Research with Human Subjects at California State University, Fresno, your proposal meets minimal risk criteria according to section 3.3.7: Research in which the risks of harm anticipated are not greater, probability and magnitude, than those ordinarily encountered in daily life or during the performance of routine physical or psychological examinations or tests.

The Research Committee may periodically wish to assess the adequacy of research process.

If, in the course of the study, you consider making any changes in the protocol or consent form, you must forward this information to the Research Committee prior to implementation unless the change is necessary to eliminate an apparent immediate hazard to the research participant(s).

This study expires: August 27, 2019

The Research Committee is authorized to periodically assess the adequacy of the consent and research process. All problems having to do with subject safety must be reported to the Research Committee. Please maintain proper data control and confidentiality.

If you have any questions, please contact me through the CSU, Fresno School of Nursing Research Committee at symiller@csufresno.edu.

Sincerely,

Syluic kelle

Sylvia Miller, EdD, RN, FNP-C

School of Nursing, Research Committee, Chair 
APPENDIX H: PREGNANCY CARE CENTER APPROVAL 


\section{(A) PREGNANCY CARE CENTER}

June 7,2018

Committee for the Protection of Human Subjects

Haak Administrative Center, $4^{\text {th }}$ Floor

Henry Madden Library

California State University, Fresno

$\mathrm{M} / \mathrm{S} \mathrm{ML} 54$

Fresno, CA 93740-8014

\section{Subject: Site Approval Letter}

Dear Members of the Committee:

This letter acknowledges that I have received and reviewed a request by Mrs. Gretchen Ezaki, RN, DNP student, to conduct a qualitative research project entitled, "Qualitative and Quantitative Assessment of a Breastfeeding Training Program Designed Particularly for Infants with Congenital Anomalies and Defects." I approve of this research to be conducted at our facility. It will be conducted at our Medical Meeting, August 2018 with our staff and volunteer nurses.

Mrs. Ezaki will be instructing the nurses how to use her algorithms to teach nurses and thus their patients how to successfully breastfeed with an emphasis on infants with congenital anomalies and defects. Her teaching algorithms will be taught to our nurses, role played, and then reviewed for strengths, weaknesses, and overall usefulness of the algorithms. Her research will take place after normal business hours with our staff/volunteers so there will be no patient contact or patient data reviewed.

Mrs. Ezaki will be obtaining and supplying a copy of her project approval to Pregnancy Care Center prior to conducting her research.

If we have any concerns or need additional information, we will contact the Fresno State Committee for the Protection of Human Subject at (559) 278-2448 or Marykelly@csufresno.edu

If there are any questions, please contact my office

Kelli Klassen, RN, Director of Nurses

559-237-0789

kelli@pregnancycarecenter.com

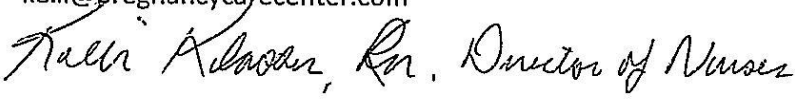

Dr. George Gonzalez, Medical Director

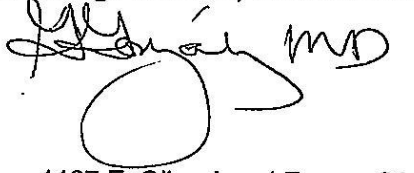

1127 E. Olive Ave. | Fresno CA 93728| ph: (559) 237-0789 | fax: (559)237-0984 | info@pregnancycarecenter.com Client Site: www.PregnancyCareCenter.com | Ministry Site: www.Ministry.PregnancyCareCenter.com 
APPENDIX I: FACILITATORS AND BARRIERS 
Breastfeeding Training Program Focus Group Responses

Relevant responses sorted by question and coded as facilitators and barriers

PCC focus group in standard print. Snowball focus group in italics.

\section{Question 1 What are your thoughts about the teaching/learning you just participated in}

\begin{tabular}{|l|l|}
\hline Facilitators & Barriers \\
\hline It was good & $\begin{array}{l}\text { I learned a lot but it was a lot at one } \\
\text { time...because of those various } \\
\text { situations it was a little confusing to me. } \\
\text { I had a hard time keeping that all } \\
\text { straight...(But I do think having the } \\
\text { paper was very beneficial) }\end{array}$ \\
\hline $\begin{array}{l}\text { v... But I do think having the paper was } \\
\text { very beneficial }\end{array}$ & We had to refer to the paper too \\
\hline It was very thorough & \\
\hline Very educational & \\
\hline $\begin{array}{l}\text { I like the role play too. Interacting, you } \\
\text { know, instead of just teaching them, but } \\
\text { asking and getting the feedback, and going } \\
\text { off of that }\end{array}$ & \\
\hline I like the role play & \\
\hline $\begin{array}{l}\text { Better way of learning (role playing) } \\
\text { I think the role playing is an important } \\
\text { part..it helps you remember what you're }\end{array}$ & \\
\hline
\end{tabular}




\begin{tabular}{|c|c|}
\hline going to try to teach. & \\
\hline $\begin{array}{l}\text { I thought it was helpful that you provided } \\
\text { many methods for us to learn by. You } \\
\text { provided the lecture part. You provided the } \\
\text { performance demonstration. You provided } \\
\text { feedback immediately. You provided the } \\
\text { role playing and then we had the examples } \\
\text { we could follow while we each did the role } \\
\text { playing }\end{array}$ & \\
\hline $\begin{array}{l}\text { Even the pre-test because we kind of go off } \\
\text { of our own experience and then you get to } \\
\text { see what people really know and then you } \\
\text { can teach well, hey you did miss this so let } \\
\text { me give you more information on that part }\end{array}$ & \\
\hline It was very informative & \\
\hline I like how interactive it was & \\
\hline It was great. The role-playing was great & \\
\hline $\begin{array}{l}\text { Having a hands-on baby was a good tool, a } \\
\text { perfect tool }\end{array}$ & \\
\hline $\begin{array}{l}\text { The small group was actually really nice } \\
\text { too, so we could work together and discuss }\end{array}$ & \\
\hline It was very & \\
\hline
\end{tabular}


Question 2-What do you think are the strengths of the learning you just completed

\begin{tabular}{|l|l|}
\hline Facilitators & Barriers \\
\hline How much you learned & \\
\hline $\begin{array}{l}\text { The best part is reassuring the mother. It's } \\
\text { very difficult to breastfeed the first time }\end{array}$ & \\
\hline $\begin{array}{l}\text { having the nurse be able to tell them that } \\
\text { you're not alone. People think that you do it } \\
\text { automatically. You just put the baby to } \\
\text { breast and there it goes, but that's not the } \\
\text { way it is. }\end{array}$ & \\
\hline $\begin{array}{l}\text { It was very educational } \\
\text { I think the role play was helpful for me } \\
\text { particularly }\end{array}$ & \\
\hline $\begin{array}{l}\text { The whole knowledge that you shared with } \\
\text { us is very valuable and it's powerful when } \\
\text { it's learned }\end{array}$ & \\
\hline The role playing \\
\hline Role playing
\end{tabular}




\begin{tabular}{|l|l|}
\hline $\begin{array}{l}\text { Switching roles like being a nurse and a } \\
\text { mom so we can see both sides }\end{array}$ & \\
\hline $\begin{array}{l}\text { referencing the algorithm is effective to } \\
\text { demonstrate that we were thorough and } \\
\text { followed everything for effective teaching }\end{array}$ & \\
\hline $\begin{array}{l}\text { For someone with no breastfeeding } \\
\text { experience, holding the baby and figuring it } \\
\text { out will help me share with the mom what to } \\
\text { do }\end{array}$ & \\
\hline
\end{tabular}

Question 3-What do you think are the weaknesses of the program you just completed

\begin{tabular}{|l|l|}
\hline Facilitators & Barriers \\
\hline $\begin{array}{l}\text { I think we learn kind of better that way } \\
\text { sometimes [role paying and having fun], but } \\
\text { it depends on the environment. If you feel } \\
\begin{array}{l}\text { comfortable you open up more. You're more } \\
\text { willing to learn so I appreciated that part of it } \\
\text { (this was disagreeing with the role-play } \\
\text { letting learners get off track) }\end{array}\end{array}$ & $\begin{array}{l}\text { when you went over the algorithm for } \\
\text { the heart defect and the cleft palate } \\
\text { too much at once }\end{array}$ \\
\hline The atmosphere was very nice & Not being able to read this \\
\hline no pressure. I liked that & $\begin{array}{l}\text { I think for me it would be helpful to } \\
\text { do each one separately }\end{array}$ \\
\hline
\end{tabular}




\begin{tabular}{|l|l|}
\hline It was well prepared & $\begin{array}{l}\text { When you role-play it's easy to get off } \\
\text { track and have conversations ... and } \\
\text { have a little too much fun... }\end{array}$ \\
\hline $\begin{array}{l}\text { doing the basic normal baby there was a } \\
\text { thing about talking to me if you have } \\
\text { questions to ask...I think that's very } \\
\text { important because when the kid does have } \\
\text { problems, mom needs to know that she can } \\
\text { come back. }\end{array}$ & $\begin{array}{l}\text { to highlight the importance of feeding } \\
\text { the baby exactly for the sicknesses and }\end{array}$ \\
\hline \hline & The vitamin A part \\
\hline & Maybe the vitamin A instead of \\
& vitamin D?
\end{tabular}

Question 4: What changes would you recommend to the program you just completed

\begin{tabular}{|l|l|}
\hline Facilitators & Barriers \\
\hline It was interesting learning the challenges that & $\begin{array}{l}\text { demonstrate how to latch a baby } \\
\text { because that could be really helpful... } \\
\text { like grabbing as much of the areola } \\
\text { and everything as possible }\end{array}$ \\
\hline & $\begin{array}{l}\text { It depends on where you are doing it. } \\
\text { If you are doing it in Africa vs }\end{array}$ \\
\hline
\end{tabular}




\begin{tabular}{|c|c|}
\hline & $\begin{array}{l}\text { America...You'd have to fine tune it } \\
\text { for the environment. }\end{array}$ \\
\hline & $\begin{array}{l}\text { you have to get a little personal with } \\
\text { this and I don't know how--you have } \\
\text { to get personal--so you better tell them } \\
\text { we're going to be using our breasts or } \\
\text { whatever. }\end{array}$ \\
\hline & We're going to be touching \\
\hline & $\begin{array}{l}\text { to break apart when you're talking } \\
\text { about the challenging baby, about the } \\
\text { heart defect, the chromosomal } \\
\text { anomaly, and the cleft lip and palate. } \\
\text { Make them separate. Separate } \\
\text { modules. }\end{array}$ \\
\hline & $\begin{array}{l}\text { As we are doing the troubleshooting, } \\
\text { the negative aspects of babies born } \\
\text { with birth defects. That we, maybe, } \\
\text { role play that this baby has a cardiac } \\
\text { defect and how would you help them } \\
\text { as a nurse, instead of the baby being a } \\
\text { normal baby and you walking through } \\
\text { and verbally saying if this was the } \\
\text { case we would do this. }\end{array}$ \\
\hline & $\begin{array}{l}\text { I don't know what the survival rate for } \\
\text { any type of prematurity is in Kenya }\end{array}$ \\
\hline
\end{tabular}




\begin{tabular}{|l|l|}
\hline but maybe, I guess, address a little bit \\
more what to do with premature \\
babies
\end{tabular}

Question 5-how prepared do you feel to teach breastfeeding to a new mom

\begin{tabular}{|l|l|}
\hline Facilitators & Barriers \\
\hline $\begin{array}{l}\text { Well, on a scale of } 1 \text { to } 10 \ldots . \text { I'd say about a } \\
\text { seven. I mean I don't know it all but you } \\
\text { gave us a lot of really good information }\end{array}$ & If you were a 10 before and a 10 after \\
& versus a one before and a 5 after \\
\hline $\begin{array}{l}\text { Really good information } \\
\text { while, but } 10\end{array}$ & Or have you ever breastfed or taught \\
anyone to breastfeed
\end{tabular}


Question 6-How well prepared do you feel to assist a mom in attempting to breastfeed an infant with an anomaly or defect

\begin{tabular}{|l|l|}
\hline Facilitators & Barriers \\
\hline $\begin{array}{l}\text { I think it's kind of like a just go for it kind of } \\
\text { thing...For nursing (referring to } \\
\text { breastfeeding) I feel like it's more hands-on, } \\
\text { so you gave us the basics. We teach it. It's } \\
\text { kind of like you hear it, you try it, you teach } \\
\text { it, so that's basically what we did. Once we } \\
\text { teach it and see if they get it, that's the only } \\
\text { way we're going to know, so I feel } \\
\text { comfortable going to someone I didn't know } \\
\text { and trying to teach them }\end{array}$ & \begin{tabular}{l} 
Probably less \\
\hline
\end{tabular} \\
\hline $\begin{array}{l}\text { The second one (referring to the } \\
\text { algorithm) was harder than the first one }\end{array}$ \\
\hline $\begin{array}{l}\text { I go ask for help. I'd feel less prepared. } \\
\text { I mean, I'd probably do cleft lip, } \\
\text { Downs...what you're talking about } \\
\text { with severe defects, I'd want more } \\
\text { practice. }\end{array}$ \\
\hline
\end{tabular}




\begin{tabular}{|c|c|}
\hline & Yes. More practice \\
\hline & I'd say more like four instead of one \\
\hline & $\begin{array}{l}\text { it's kind of hard to transition for me } \\
\text { going into pathophysiology }\end{array}$ \\
\hline & $\begin{array}{l}\text { we here (their group) would never } \\
\text { attempt a cleft palate }\end{array}$ \\
\hline & Separate (the algorithm for anomalies) \\
\hline & $\begin{array}{l}\text { Three separate (the algorithms for } \\
\text { anomalies) }\end{array}$ \\
\hline & More information \\
\hline & $\begin{array}{l}\text { Can you make even a fourth } \\
\text { because...the Downs baby has the heart } \\
\text { defect and the cleft palate along with } \\
\text { them, so then you're dealing with what } \\
\text { do you do with all } 3 \text { of them. }\end{array}$ \\
\hline $\begin{array}{l}\text { I feel pretty confident. I think that I would } \\
\text { want to make sure they know what is safe } \\
\text { and that safety is the most important thing }\end{array}$ & Common issues and what to do \\
\hline $\begin{array}{l}\text { As long as I knew there was going to be } \\
\text { follow up with someone else, especially that } \\
\text { there will be doctors following up with the }\end{array}$ & $\begin{array}{l}\text { I could show them the basics, but I } \\
\text { would need to practice and learn a } \\
\text { little bit more }\end{array}$ \\
\hline
\end{tabular}




\begin{tabular}{|l|l|}
\hline baby .... & \\
\hline & $\begin{array}{l}\text { I think we have the basics ok, but I'd } \\
\text { need to learn more, more details... }\end{array}$ \\
\hline
\end{tabular}


APPENDIX I: FOCUS GROUP MEMOS 
Sunday focus group memo

4 attendees

Time frames seemed good

One was a Land D nurse, one a recent grad who is starting in NICU. The other 2 are experienced nurses but breast fed their own children so breastfeeding was familiar to them.

They all role played willingly and used the OSCEs correctly.

The discussion was good but not a lot of helpful recommendations because they were very positive about the program and comfortable teaching breastfeeding.

After the program the new NICU nurse (who has no children) said she felt like it was exactly what she needed to learn as a beginning NICU nurse. 
Monday focus group memo

15 attendees

Took a few minutes to get the group on track. We started almost 15 minutes after the hour.

Began with the consent and pretest - they seemed very intent on doing well on the pretest. It was 25 after when most were done. I was worried about time so I started even though a couple were still doing the pretest.

Then I did the overview of what the program is and why I am developing it. I told them about my plan to take the program to Kenya in July 2019. This took 15 minutes because they asked some questions.

Then I demonstrated by using a volunteer as a mom to role play basic breastfeeding teaching. It was about 6:40 when we started the role-play demo.

Then I turned it over to them to practice through role playing. Most role played well. They really seemed to enjoy role playing. The "mom" asked real-life new mom questions. I was watching the clock so after about 20 minutes (7:10) I asked them to start checking each other off. They were supposed to have the "mom" or observer for the groups of 3 use the OSCE and the "nurse" use the algorithm, but many of the "nurses" looked at the OSCE as they went.

One group followed the OSCE meticulously (there were nurse educators in the group). The check off went relatively quickly but two groups had 3 so it took approximately 15 minutes to check off.

One group did pseudo role-play. They used the doll but talked about what they would do and say rather than doing it. That group had 2 older nurses (probably have not done much simulation) and 1 nurse who is a post-partum nurse so she was very comfortable with the material.

We then went to the algorithm for anomalies about 7:20. I demo'd it with the same volunteer and got them practicing quickly because I was worried about time. I only let them practice for a few minutes and told them to start checking off because I wanted to have 20 minutes for the discussion. The group who did not role play well with the first algorithm did not role play at all the $2^{\text {nd }}$ time. They talked about what to assess and what to do, but did not role play it. On the $2^{\text {nd }}$ check off I noticed most groups used the OSCE rather than the algorithm as their guide. Due to the time I did not stop them. At 7:35 I gave them a 5-minute warning to finish quickly.

We began the discussion about 7:40. 
The discussion went well. Many comments brought nods of agreement from the group. The positive comments about role playing being good brought lots of nods - including from the two older nurses in the group who did not role play. Then there were lots of scattered comments. The question about improvement again got lots of nods from the rest of the group that the anomalies algorithm needs to be simplified.

Learners did the posttest and we finished about 5 after. Most of the group was not in a rush to leave and they talked to me and each other for another 10 minutes or so. 
APPENDIX J: PERMISSISON TO USE IMAGE 
James Byme cjames byme@outlookcoms
Re: Requesting permission to use an image

Bing Maps

Thanks for reaching out
Request is Approved.

+ Get more app

From: Gretchen Eraki creretchen.ezaki fifresnocitycollepe.edus
Sent: Friday, March 29, $201911: 19$ AM

To: infoalucluamaterinty. org
Subject: Requesting permission to use an image

To Lucina Foundation:

am requesting permission to use the following image in a doctoral project which I will be submitting for publication. As part of a Doctor of Nursing practice degree I have designed a program to train bedside nurses to support breastteeding including for infants with commmon congenital anomalies and defects

mage in the algorithm for feeding infants with trisomy 21

Thank vou for considering my request,
Gretchen Ezaki

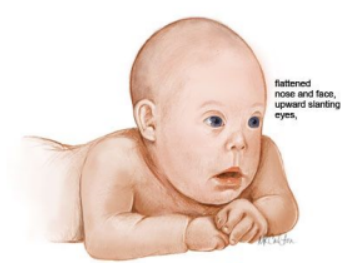

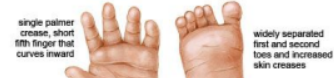

